\title{
O Sistema de Economia Circular e a Agenda 2030: Análise da Evolução em Portugal
}

The Circular Economy and the 2030 Agenda: Progress Analysis in Portugal 


\section{Resumo}

A crescente consciencialização da sociedade para os problemas ambientais, aquecimento global, consumo massivo de recursos e aumento das desigualdades, tem exercido uma forte pressão sobre os países e organizações, estando na base da Agenda Global 2030. Neste contexto, a Economia Circular é considerada uma abordagem fundamental para alcançar alguns desses objetivos. Este trabalho visa discutir a relação entre a Economia Circular e o Desenvolvimento Sustentável e fazer uma análise comparativa, no contexto europeu, à evolução de Portugal para alguns dos indicadores específicos estabelecidos na Agenda 2030. Para tal foi desenvolvida uma pesquisa exploratória e descritiva, que incluiu a revisão de literatura e a análise e tratamento de dados secundários. A análise indica que, apesar da evolução positiva em vários dos indicadores analisados, o desempenho português, em termos globais, está abaixo do desempenho médio europeu. Adicionalmente, para alguns indicadores a evolução ocorreu em sentido contrário ao desejável. Apesar da sociedade, e cidadãos, estarem mais conscientes e atentos a produtos, processos e entidades "sustentáveis", há ainda um longo caminho a percorrer para que os princípios da Economia Circular e do Desenvolvimento Sustentável sejam plenamente reconhecidos e aplicados.

Palavras-chave: Agenda 2030, Desenvolvimento Sustentável, Economia Circular, Portugal, União Europeia

\section{Abstract}

Society's growing awareness of environmental problems, global warming, massive consumption of resources, and increasing inequalities, has put strong pressure on countries and organizations, underpinning the Global Agenda 2030. In this context, the Circular Economy is increasingly recognized as a fundamental approach to achieve some of these goals. The aim of the paper is to discuss the relationship between Circular Economy and Sustainable Development and to provide a comparative analysis, in the European context, of Portugal's evolution for some of the specific indicators established in the 2030 Agenda. To this end, an exploratory and descriptive research was developed, which included a literature review and the analysis and treatment of secondary data. Despite the positive evolution in several indicators, the descriptive analysis indicates that the Portuguese performance, in overall terms, is below the European average performance. Additionally, for some indicators the evolution has gone in the opposite direction than desirable. Society, and citizens, are increasingly aware and attentive to "sustainable" organizations, products, and processes. Nevertheless, there is still a long way to go to fully recognize and apply the Circular Economy and Sustainable Development principles.

Keywords: The 2030 Agenda, Circular Economy, Sustainable Development, Portugal, European Union 


\section{Introdução}

0 rápido processo de globalização dos sistemas produtivos tornou as cadeias de valor progressivamente globais. Esta evolução, associada ao crescimento da população, da riqueza e do consumo, exercem uma pressão insustentável sobre o planeta e os seus recursos. 0 reconhecimento de que o modelo da economia linear "extrair-consumirdescartar" é um modelo insustentável está na base da "Agenda Global para a Sustentabilidade" adotada pelas Organização das Nações Unidas (UN) em 2015.

0 quadro de Objetivos de Desenvolvimento Sustentável (ODS), aprovado pela UN, é abrangente e multidisciplinar, englobando 17 objetivos gerais, com múltiplas metas, e abarcando as vertentes económica, social e ambiental. Nesse sentido, é necessário realçar que os ODS, e as suas metas, só poderão ser alcançados substituindo 0 atual paradigma de produção linear por um sistema de organização económica assente nos pressupostos da Economia Circular (EC). Um sistema económico assente na EC procura ser regenerativo, quer ao nível da produção, quer ao nível do consumo, uma vez que procura a implementação de processos de produção tecnologicamente inovadores e eficientes, que reduzam o consumo e extração de recursos finitos, promovam a reconversão e reutilização dos resíduos, bem como a utilização de "energias limpas". Este sistema visa respeitar os limites do planeta assumindo como princípios a reutilização, a reciclagem, a reparação e o redesign (Agência Europeia do Ambiente [EEA], 2016; Borrello et al., 2020; Ghisellini et al., 2016; Suárez-Eiroa et al. 2019). Alguns estudos recentes como os de Aid et al. (2016), Hysa et al. (2020), Lieder e Rashid (2016), mostram que as taxas de reciclagem, bem como a inovação ambiental e na reciclagem são fatores significativos de desenvolvimento sustentável e de crescimento económico. Também Schroeder et al. (2018) mostram que as práticas e princípios da EC contribuem diretamente para alcançar vários ODS. Entre alguns dos ODS está a redução das emissões de gases com efeito de estufa, redução de resíduos, drenagem de águas residuais, redução no consumo de materiais, poupança energética e utilização de energias renováveis. Neste modelo, todos os agentes económicos, sejam eles consumidores, empresas, organizações, governos ou países, têm um papel ativo que terá que ser coordenado e integrado num plano de ação que permita atingir as metas definidas. De acordo com D'Amato (2021), a prossecução da sustentabilidade requer processos de cocriação e co-governação, envolvendo atores locais e internacionais, onde se incluem académicos, decisores políticos, indústrias, técnicos e profissionais e as comunidades. Gentiloni (2020) refere que as vertentes económica, social e ambiental, têm que ser abordadas de forma holística integrando ações coordenadas de todos os países. Nesse sentido, a implementação de políticas e medidas destinadas a atingir os ODS constitui o caminho para alcançar um mundo melhor, onde as pessoas possam aumentar o seu nível de vida e bem-estar e viver em harmonia e respeito pelo planeta.

Com efeito, estas questões assumem uma relevância crescente e determinante na agenda dos países, organizações e empresas, que procuram definir e adotar políticas e estratégias que possam potenciar e promover práticas e princípios sustentáveis. Contudo, para que essa definição possa ser eficaz é importante fazer, previamente, um diagnóstico à situação existente, daí a relevância deste estudo. Com este trabalho espera-se obter maior conhecimento sobre a temática, bem como 
identificar 0 posicionamento relativo de Portugal, no que se refere ao cumprimento das metas e ODS. Assim, foi definido um duplo objetivo. Por um lado, pretende-se analisar e discutir os conceitos e relações entre a EC e o Desenvolvimento Sustentável (DS) e a sua relevância para o alcance dos objetivos da Agenda 2030. Por outro, pretende-se analisar, numa perspetiva comparada com a média da UE, a evolução ocorrida em Portugal para um conjunto de ODS selecionados. Para atingir os objetivos foi desenvolvida uma pesquisa exploratória e descritiva, que incluiu a revisão de conceitos fundamentais e a análise e tratamento de dados secundários recolhidos da Eurostat database. Nesse sentido, começamos por apresentar a abordagem metodológica. De seguida, o enquadramento e revisão teórica. $\mathrm{Na}$ secção 3 apresenta-se a evolução e análise comparativa para alguns indicadores e metas de ODS selecionados. Por último, apresentamse as principais conclusões.

\section{Abordagem metodológica}

Atendendo aos objetivos deste estudo, foi adotada uma pesquisa exploratória e descritiva. De acordo com Gil (2010), o objetivo da pesquisa exploratória será explorar um problema, obter informações adicionais e aprimorar as ideias sobre o fenómeno ou problemática a estudar. Para Richardson (1999) a pesquisa exploratória aprofunda os conhecimentos das características de determinado fenómeno para procurar explicações das suas causas e consequências. Normalmente consiste no primeiro passo para quem pretende estudar uma temática sobre a qual não detém suficiente conhecimento e, como tal, constitui o primeiro passo para estabelecer as bases para o desenvolvimento de estudos futuros. A pesquisa é também considerada descritiva na medida em que procura descrever, analisar, recolher e interpretar dados sobre o fenómeno ou a problemática em estudo (Gil, 2010).
Nesse sentido, numa primeira fase serão revistos os conceitos fundamentais sobre a EC e o DS, pela análise da literatura relevante, tendo sido identificadas as relações entre os dois conceitos. De seguida, e partindo da revisão teórica e da categorização elaborada por Schroeder et al. (2018), foram selecionados 20 indicadores com um maior potencial para promover 0 alcance de metas dos ODS. Procedeu-se à recolha, tratamento $\mathrm{e}$ análise de dados disponíveis na base de dados do Eurostat (acessível em Eurostat database). Esses dados foram recolhidos em março de 2021. Nessa seleção procurou-se integrar diversas áreas da Agenda 2030, e considerar 0 maior número de ODS, atendendo à disponibilidade e atualidade de informação, bem como à pertinência e relação dos indicadores com a EC. A análise foi realizada numa perspetiva comparada, entre Portugal e a União Europeia (UE) a 27 (UE27) (isto é, sem integrar o Reino Unido), por forma a identificar a posição relativa do nosso país. 


\section{Enquadramento e revisão teórica}

A crescente consciencialização da sociedade para problemas globais tais como 0 aquecimento global, consumo massivo de recursos, aumento das desigualdades, problemas ambientais, têm exercido uma forte pressão para que os países e organizações assumam uma agenda progressivamente guiada pelos objetivos e princípios da EC e do DS. Vários autores, Bonciu (2014), Ghisellini et al. (2016), Korhonen et al. (2018), Schroeder et al. (2018) apontam que o desafio do DS e de implementação de sistemas económicos assentes na EC, isto é, que promovam o crescimento económico e a equidade social, protegendo 0 ambiente e minimizando a extração e consumo de recursos finitos, despertou 0 interesse dos países, dos decisores, das empresas e dos académicos. Apesar disso, a questão de saber se a EC constitui uma abordagem para atingir e promover o DS e os seus objetivos não é consensual. Millar et al. (2019), indicam que 0 conceito de $\mathrm{EC}$, atendendo à sua compreensão atual, deve ser considerado e entendido como um modelo mais sustentável ambientalmente, quando comparado com o modelo da economia "linear" e não como um modelo ideal para alcançar o DS.

Apesar dos conceitos de EC e DS serem, com frequência, usados conjuntamente, são claramente distintos pelo que é importante, por um lado, distingui-los e, por outro, procurar identificar e perceber as relações entre eles.

\subsection{Desenvolvimento Sustentável}

${ }^{26}$ O Relatório Brunddtland, publicado em 1987, foi elaborado pela Comissão Mundial sobre o Meio Ambiente e Desenvolvimento. Esta comissão, criada em 1983 pela Assembleia Geral da ONU, e
Os desafios da implementação do DS têm-se tornado cada vez mais evidentes ao longo dos últimos 30 anos (Cecchin et al. 2021). Com efeito, embora as referências às preocupações ambientais remontem à década de 60 do século passado, o conceito de DS, e a necessidade de integrar as questões ambientais e sociais na definição de políticas económicas, é claramente identificado e assumido no Relatório Brunddtland ${ }^{26}$ - Our Common Future. 0 relatório define o conceito de DS como "it meets the needs of the present without compromising the ability of future generations to meet their own needs (UN, 1987, p.24) e indica claramente que a agenda política e económica tem que integrar e conciliar as questões ambientais, sociais e de sustentabilidade na definição de políticas de crescimento e desenvolvimento. Desde então, outros acontecimentos foram importantes e determinantes para que o desenvolvimento sustentável integrasse a agenda política e económica dos países e organizações, nomeadamente, e entre outras, as Cimeiras da Terra e do Milénio, o protocolo de Quioto e a Agenda 2030. A Agenda 2030 definiu um plano de ação ambicioso e universal, a favor das pessoas, do planeta e da prosperidade. Traçando o caminho para os próximos 15 anos, este plano integra os 17 ODS (quadro 1) (e 169 metas), os quais são indivisíveis e interligados de forma a garantir e equilibrar os resultados nas 3 dimensões do DS: a económica, social e ambiental (UN, 2015). presidida por Harlem Brundtland, apontou, pela primeira vez, a necessidade de adotar modelos de crescimento económico que conciliem e integrem as preocupações ambientais e sociais. 
Quadro 1. Os 17 ODS

\begin{tabular}{|c|c|}
\hline 1. Erradicar a pobreza & Erradicar a pobreza em todas as suas formas, em todos os lugares. \\
\hline 2. Erradicar a fome & $\begin{array}{l}\text { Erradicar a fome, alcançar a segurança alimentar, melhorar a nutrição e promover } \\
\text { a agricultura sustentável. }\end{array}$ \\
\hline 3. Saúde de qualidade & $\begin{array}{l}\text { Garantir o acesso à saúde de qualidade e promover o bem-estar para todos, em } \\
\text { todas as idades. }\end{array}$ \\
\hline 4. Educação de qualidade & $\begin{array}{l}\text { Garantir o acesso à educação inclusiva, de qualidade e equitativa, e promover } \\
\text { oportunidades de aprendizagem ao longo da vida para todos. }\end{array}$ \\
\hline 5. Igualdade de género & Alcançar a igualdade de género e empoderar todas as mulheres e raparigas. \\
\hline 6. Água potável e saneamento & $\begin{array}{l}\text { Garantir a disponibilidade e a gestão sustentável da água potável e do saneamento } \\
\text { para todos. }\end{array}$ \\
\hline $\begin{array}{l}\text { 7. Energias renováveis e } \\
\text { acessíveis }\end{array}$ & Garantir o acesso a fontes de energia fiáveis, sustentáveis e modernas para todos. \\
\hline $\begin{array}{l}\text { 8. Trabalho digno e } \\
\text { crescimento económico }\end{array}$ & $\begin{array}{l}\text { Promover o crescimento económico inclusivo e sustentável, o emprego pleno e } \\
\text { produtivo e o trabalho digno para todos. }\end{array}$ \\
\hline $\begin{array}{l}\text { 9. Indústria, inovação e } \\
\text { infraestruturas }\end{array}$ & $\begin{array}{l}\text { Construir infraestruturas resilientes, promover a industrialização inclusiva e } \\
\text { sustentável e fomentar a inovação. }\end{array}$ \\
\hline 10. Reduzir desigualdades & Reduzir as desigualdades no interior dos países e entre países. \\
\hline $\begin{array}{l}\text { 11. Cidades e comunidades } \\
\text { sustentáveis }\end{array}$ & $\begin{array}{l}\text { Tornar as cidades e as comunidades mais inclusivas, seguras, resilientes e } \\
\text { sustentáveis. }\end{array}$ \\
\hline $\begin{array}{l}\text { 12. Produção e consumo } \\
\text { sustentáveis }\end{array}$ & Garantir padrões de consumo e de produção sustentáveis. \\
\hline 13. Ação climática & $\begin{array}{l}\text { Adotar medidas urgentes para combater as alterações climáticas e os seus } \\
\text { impactos. }\end{array}$ \\
\hline 14. Proteger a vida marinha & $\begin{array}{l}\text { Conservar e usar de forma sustentável os oceanos, mares e os recursos marinhos } \\
\text { para o desenvolvimento sustentável. }\end{array}$ \\
\hline 15. Proteger a vida terrestre & $\begin{array}{l}\text { Proteger, restaurar e promover o uso sustentável dos ecossistemas terrestres, } \\
\text { gerir de forma sustentável as florestas, combater a desertificação, travar e } \\
\text { reverter a degradação dos solos e travar a perda de biodiversidade. }\end{array}$ \\
\hline $\begin{array}{l}\text { 16. Paz, justiça e instituições } \\
\text { eficazes }\end{array}$ & $\begin{array}{l}\text { Promover sociedades pacíficas e inclusivas para o desenvolvimento sustentável, } \\
\text { proporcionar o acesso à justiça para todos e construir instituições eficazes, } \\
\text { responsáveis e inclusivas a todos os níveis. }\end{array}$ \\
\hline $\begin{array}{l}\text { 17. Parcerias para a } \\
\text { implementação dos objetivos }\end{array}$ & $\begin{array}{l}\text { Reforçar os meios de implementação e revitalizar a parceria global para o } \\
\text { desenvolvimento sustentável. }\end{array}$ \\
\hline
\end{tabular}

Fonte: adaptado de UN (2015)

0 quadro dos 17 ODS indica que há um plano e objetivos ambiciosos para o DS e as suas vertentes, englobando as áreas da produção, consumo energético, proteção social e de 
género, proteção ambiental, desenvolvimento humano e condições de vida, entre outras. Com efeito, já Elkington (1994) havia alertado que o DS e a proteção ambiental iriam constituir um desafio central para os países e governos sendo necessária uma abordagem abrangente e que envolvesse um amplo conjunto de stakeholders, vetores da sociedade e políticas governamentais. Neste âmbito, Mitchel e McDonald (1995) identificam e definem os princípios de DS, os quais foram desenvolvidos e adaptados por Curwell e Cooper (1998).

Figura 1. Princípios do desenvolvimento sustentável

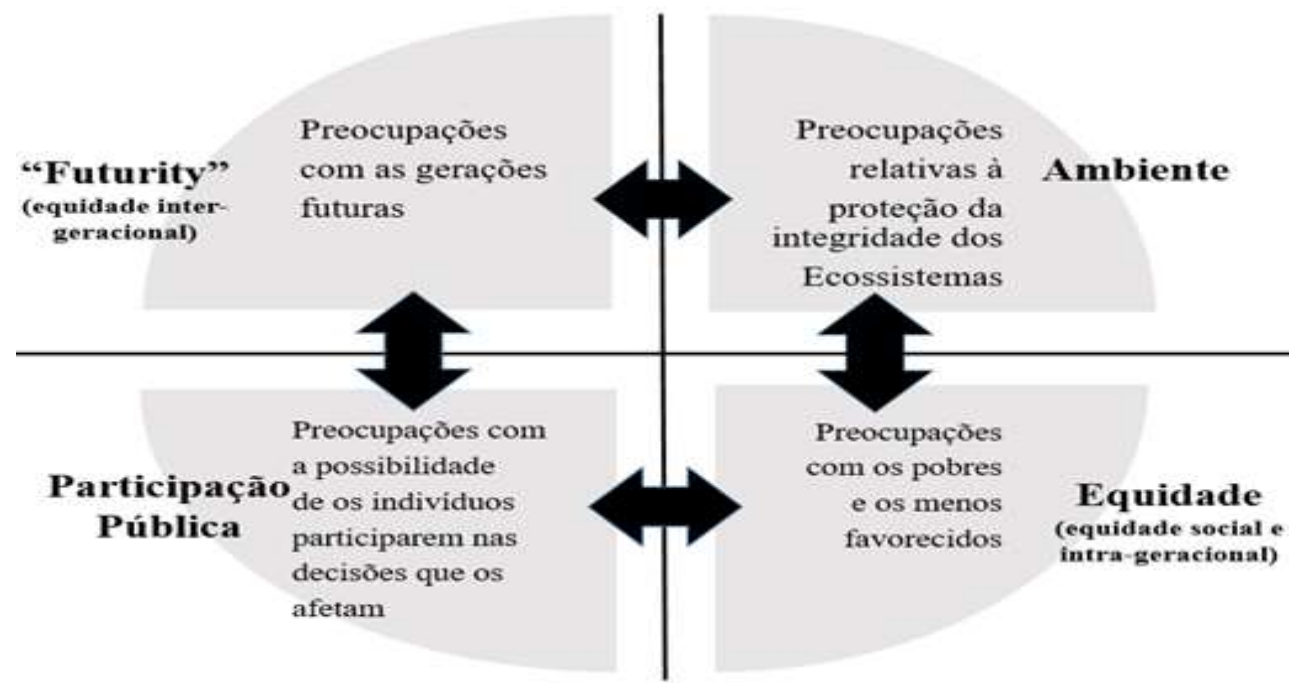

Fonte: Adaptado de Curwell e Cooper (1998, p.20)

\subsection{Economia Circular}

0 conceito de EC tem recebido um amplo e crescente interesse, quer de académicos, quer de profissionais, e tem sido analisado no âmbito de diferentes áreas de pesquisa, desde a Engenharia, Economia, Ecologia, Arquitetura e Urbanismo, Biologia, entre outras. 0 sistema de EC é visto como um modo de operacionalizar e implementar o DS (Cecchin et al. 2021; Kirchher et al. 2017; VasiljevicShikaleska, et al., 2017) existindo, assim, muitos conceitos e representações deste sistema alternativo ao sistema produtivo linear. De acordo com a EEA (2016), a EC é um sistema que procura respeitar os limites do planeta através de uma maior utilização de recursos renováveis e recicláveis, redução do consumo de matérias, energia e redução das emissões poluentes. Suárez-Eiroa et al. (2019, p.958) definem o conceito de forma mais precisa:

A economia circular é um sistema regenerativo de produção e consumo que visa manter as taxas de extração de recursos, de geração de resíduos e de emissões em valores adequados aos limites do planeta, através da circularidade do sistema, redução do seu tamanho e manutenção do valor dos recursos o maior tempo possível dentro do sistema, apoiando-se principalmente no design e educação, e com 
capacidade de implementação em qualquer escala ${ }^{27}$.

Na perspetiva de Hysa et al. (2020), a EC é entendida como um sistema económico que interliga os níveis de micro-meso-macro, centrando-se nos $4 R$ - redução, reutilização, reciclagem e recuperação de materiais em atividades de produção-consumo, com 0 objetivo de alcançar, pela inovação dos processos de produção e consumo, o desenvolvimento sustentável.

Portanto, a definição de EC não constitui uma tarefa fácil, podendo apresentar diferentes perspetivas de acordo com a área de pesquisa a que se refere. De facto, a revisão da literatura sobre a EC indica que não existe consenso, quer quanto à origem, quer quanto ao próprio conceito. Kirchher et al. (2017), Khitous et al. (2020), Korhonen et al. (2018), Murray et al. (2017), bem como Prieto-Sandoval et al. (2018) apresentam uma vasta e completa revisão das definições do termo. Na perspetiva deste trabalho, não sendo determinante uma revisão exaustiva dos vários conceitos, assume-se como importante uma sintetização das suas dimensões fundamentais (figura 2).

Figura 2. Sistema de Economia Circular

PRINCÍPIOS FUNDAMENTAIS
- Redução na extração, consumo e utilização de
recursos naturais;
- Maior utilização de recursos, materiais e energias
reciclāveis e renováveis;
- Redução das emissōes poluentes;
- Maior reutilização e redução na geração de resícuos;
- Manter o valor e utilidade dos produtos e materiais o
maior tempo possivel na economia.

Fonte: Elaboração própria com base em EEA (2016 p. 9-14)

Considerando os princípios, as medidas e os benefícios do sistema de EC parece-nos que este sistema é fundamental para promover 0
DS, na medida em que a sua abordagem é abrangente e multidisciplinar, procurando dissociar o crescimento e desenvolvimento

27 Tradução dos autores 
económico da destruição de recursos naturais e da degradação do ambiente. A adoção de um sistema de EC implica a integração de todas as atividades que visem a redução, reutilização $e$ reciclagem em toda a cadeia de valor, desde a extração, produção, distribuição e consumo. Com efeito, a perspetiva da Comissão Europeia (2020) segue nesse sentido. Isto é, a mudança para a EC significa a adoção de sistemas menos dispendiosos, que geram menos resíduos, utilizam os recursos de forma mais eficiente e sustentável, ao mesmo tempo que proporcionam oportunidades de trabalho, emprego e melhor qualidade de vida. Desta forma, constitui um contributo fundamental para a Agenda 2030 e para os ODS (Comissão Europeia, 2020, p.3).

\subsection{Economia Circular e Desenvolvimento Sustentável}

A adoção e implementação da EC advém da premente necessidade de dar uma resposta aos desafios globais que decorrem das alterações climáticas, do aumento e envelhecimento da população mundial, da globalização das cadeias de valor e aumento do consumo e extração de recursos, os quais exercem uma pressão insustentável sobre 0 planeta e os seus recursos. A literatura indica que este conceito, e sua implementação, constitui uma estratégia, ainda recente, que procura a adoção de processos e sistemas económicos dissociados dos modelos lineares e progressivamente mais sustentáveis (EEA, 2016; Ghiselline et al. 2016; Murry et al.,2017). $A E C$, enquanto mecanismo para alcançar o DS, tem incidido em estratégias e medidas destinadas a reduzir a dependência da economia dos recursos naturais e finitos e a resolver ou atenuar problemas ambientais. Nesse sistema económico, baseado em modelos de negócios que substituem 0 conceito de 'fim de vida' pelas políticas de redução, reutilização alternativa, reciclagem e recuperação de materiais, assume-se como fundamental para alcançar o DS, o que implica a proteção e qualidade ambiental, prosperidade económica e equidade social, para o benefício das gerações atuais e futuras (Kirchherr et al., 2017).

Nesse sentido, há uma questão para a qual será importante procurar uma resposta. De que forma a EC poderá contribuir para os ODS? Atendendo à revisão da literatura e aos princípios e benefícios da EC apresentados na figura 2, podemos indicar que a adoção de um sistema económico assente na EC contribui para as 3 dimensões do DS: económico, social e ambiental. Com efeito, Schroeder et al. (2018), analisaram de que forma as medidas da EC permitem alcançar os ODS nos países desenvolvidos. Seguindo uma análise qualitativa, os autores confrontaram e estabeleceram as relações entre os 17 ODS com as práticas e princípios da EC. Os autores começaram por definir e explicar o tipo ou categorias de relações que existem entre as práticas de EC e os ODS identificando 5 categorias. A identificação dessas categorias, bem como os resultados dos autores são sintetizados no quadro 2. 
Quadro 2. Relação entre práticas de EC e ODS

\begin{tabular}{|c|c|c|}
\hline $\begin{array}{c}\text { Tipo/categoria } \\
\text { de relação entre } \\
\text { a EC e ODS } \\
\end{array}$ & Significado & ODS incluídos nessa relação \\
\hline $\begin{array}{l}\text { 1.Contribuição } \\
\text { direta/forte }\end{array}$ & $\begin{array}{l}\text { O cumprimento das metas e dos ODS } \\
\text { depende diretamente das práticas de EC. } \\
\text { Neste tipo de categoria de relação, é } \\
\text { praticamente impossivel alcançar os ODS e } \\
\text { suas metas sem as práticas e princípios de } \\
\text { EC. }\end{array}$ & \multirow{2}{*}{$\begin{array}{l}\text { ODS } 6 \text { (Água Potável e Saneamento), } \\
\text { ODS } 7 \text { (Energias renováveis e } \\
\text { Acessíveis), ODS } 8 \text { (Trabalho Digno e } \\
\text { Crescimento Económico); ODS } 12 \\
\text { (Produção e Consumo Sustentáveis) e } \\
\text { ODS } 15 \text { (Proteger a Vida Terrestre). }\end{array}$} \\
\hline $\begin{array}{l}\text { 2. Contribuição } \\
\text { indireta (através } \\
\text { de outros ODS e } \\
\text { suas metas) }\end{array}$ & $\begin{array}{l}\text { A contribuição da EC para atingir estes } \\
\text { ODS ocorre indiretamente através de outros } \\
\text { ODS indicando sinergias que podem ser } \\
\text { estabelecidas entre diferentes ODS através } \\
\text { das práticas de EC. }\end{array}$ & \\
\hline $\begin{array}{l}\text { 3. O progresso } \\
\text { nos ODS potencia } \\
\text { as práticas de EC }\end{array}$ & $\begin{array}{l}\text { Esta categoria indica uma relação de } \\
\text { causalidade reversa indicando que se } \\
\text { houver progresso nos ODS isso potenciará } \\
\text { a aceitação e implementação das práticas de } \\
\text { EC. }\end{array}$ & $\begin{array}{l}\text { ODS } 4 \text { (Educação de Qualidade), ODS } 9 \\
\text { (Indústria, Inovação e Infraestruturas), } \\
\text { ODS } 10 \text { (Reduzir as Desigualdades), } \\
\text { ODS } 13 \text { (Ação Climática), ODS } 16 \text { (Paz, } \\
\text { Justiça e Instituições Eficazes); ODS } 17 \\
\text { (Parcerias para a Implementação dos } \\
\text { Objetivos) }\end{array}$ \\
\hline $\begin{array}{l}\text { 4. Sem relação ou } \\
\text { relação fraca }\end{array}$ & $\begin{array}{l}\text { Esta categoria de relação aplica-se às metas } \\
\text { e ODS para as quais não se encontra } \\
\text { relação com as práticas de EC. }\end{array}$ & $\begin{array}{l}35 \text { metas incluídas nos ODS } 3 \text { (Saúde de } \\
\text { Qualidade), ODS } 5 \text { (Igualdade de } \\
\text { Género), ODS } 10 \text { (Reduzir as } \\
\text { Desigualdades), ODS } 11 \text { (Cidades e } \\
\text { Comunidades Sustentáveis) e ODS } 16 \\
\text { (Paz, Justiça e Instituições Eficazes) }\end{array}$ \\
\hline $\begin{array}{l}\text { 5. Oportunidades } \\
\text { de cooperação } \\
\text { para promover } \\
\text { práticas de EC }\end{array}$ & $\begin{array}{l}\text { Esta categoria de relação foi considerada } \\
\text { nas metas e ODS que ofereceriam } \\
\text { oportunidades para serem estabelecidas } \\
\text { iniciativas concretas de cooperação entre } \\
\text { práticas de EC e os ODS }\end{array}$ & $\begin{array}{l}\text { Todos os ODS, à exceção do ODS } 9 \text { e o } \\
\text { ODS } 16 \text {, incluem metas onde poderão ser } \\
\text { estabelecidas iniciativas concretas de } \\
\text { cooperação entre práticas de EC e os } \\
\text { ODS. }\end{array}$ \\
\hline
\end{tabular}

Fonte: adaptado de Schroeder et al. (2018, pp: 81-83)

Para Schroeder et al. (2018) parece claro que a EC contribui e é fundamental para alcançar os ODS. Também para Suárez-Eiroa et al. (2019), a EC é uma ferramenta necessária para promover o desenvolvimento sustentável. No entanto, os autores referem que essa questão não reúne consenso na literatura científica. Por exemplo, De Man e Friege (2016), referem que não há garantia de que os "sistemas circulares" trazem resultados sustentáveis, pois essas soluções têm também impactos ambientais negativos. Também Millar et al. (2019), criticam o modelo de EC e a sua contribuição para o DS sendo que para os autores a EC, no máximo, deve ser apenas considerado um modelo mais sustentável, do ponto de vista ambiental, do que o modelo de economia linear.
Apesar da controvérsia e de ser reconhecido que, do ponto de vista prático, é de difícil implementação (Kirchherr et al., 2018), na nossa perspetiva não será possível alcançar os ODS sem mudar 0 atual paradigma de produção-consumo. Esse facto é reconhecido por vários investigadores e organizações que indicam que a EC, as suas práticas e princípios constituem uma abordagem fundamental para prosseguir o DS e os objetivos da Agenda 2030 (Comissão Europeia, 2020; Ellen MacArthur Foundation, 2017; Ghisellini et al. 2016; Kirchherr et al. 2017; Korhonen et al. 2018; Murray, et al. 2017; Schroeder et al. 2018; Yuan et al. 2006). 


\section{AGENDA 2030 - Análise à evolução em Portugal}

Portugal, enquanto membro da UE, partilha do compromisso de adotar estratégias que potenciem a circularidade e a aplicação de modelos que fomentem a eficiência na utilização e valorização de recursos e que minimizem os impactos nos ecossistemas. A Agenda 2030, adotada pelas UN em 2015, definiu um conjunto de ODS sobre os quais os países terão que reportar a sua evolução. Mas em que medida esses objetivos e indicadores estão a ser implementados e alcançados?

0 objetivo desta secção será procurar uma resposta para esta pergunta. Já referimos que a Agenda 2030 constitui um projeto ambicioso e multidimensional, que requer o envolvimento de todos. Nesse sentido, é importante referir que as metas e indicadores de vários e diferentes objetivos estão interrelacionados, sendo usados para medir e aferir os resultados em vários ODS. Será feita referência a esse facto sempre que, na análise que vamos apresentar, um dado indicador/ é considerado em vários ODS.

\subsection{ODS 1 - Erradicar a pobreza}

${ }^{28}$ De acordo com o Eurostat (metainformação), as pessoas em risco de pobreza são pessoas com um rendimento disponível equivalente abaixo do limiar do risco de pobreza, que é fixado em
0 ODS 1 tem como finalidade erradicar a pobreza, em todas as suas formas e lugares. As metas e os indicadores definidos neste ODS visam garantir igualdade de direitos e acesso aos recursos económicos e naturais, a medidas e sistemas de proteção social adequados, bem como à tecnologia, propriedade e serviços financeiros e, ainda, reduzir a exposição aos fenómenos extremos relacionados com o clima e outros choques e desastres económicos, sociais e ambientais. Portanto, no âmbito deste ODS procura-se ainda garantir a mobilização de recursos financeiros destinados a apoiar a definição de programas e políticas de irradicação da pobreza nos países menos desenvolvidos e em desenvolvimento.

A análise e acompanhamento do ODS 1 procura indicar os progressos realizados na redução da pobreza multidimensional e na garantia de que as necessidades básicas dos cidadãos são satisfeitas. Nesse sentido, apresentamos a evolução dos indicadores "População em risco de pobreza"28 (figura 3) e a "Proporção das despesas públicas com serviços essenciais" (figura 4).
$60 \%$ do rendimento disponível médio nacional equivalente (após transferências sociais). 
Figura 3. População em risco de pobreza, após transferências sociais (em \% da população)

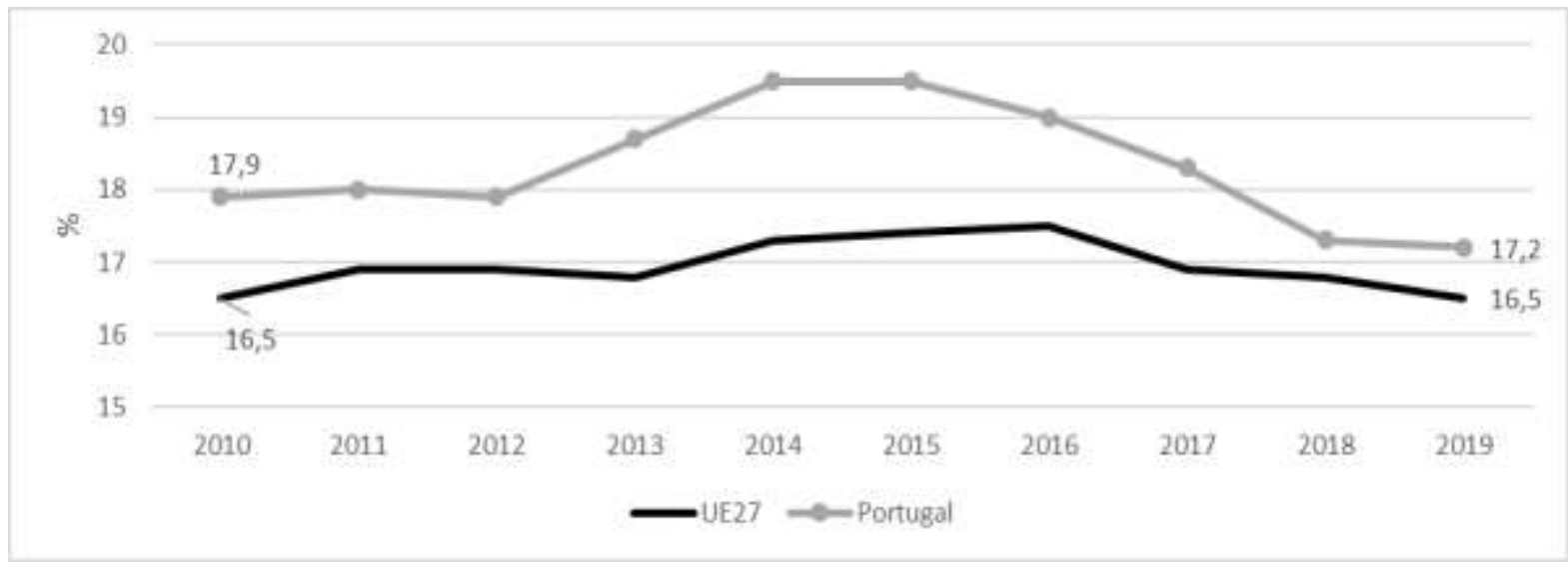

Nota: o valor de 2019 é estimado

Fonte: elaboração própria com base em Eurostat database

No que se refere à população em risco de pobreza, após transferências sociais, a população nestas condições em Portugal é superior à média europeia embora mostre uma tendência decrescente desde 2015 (figura 3).

As despesas públicas aplicadas em serviços essenciais (educação, saúde e proteção social), constituem um indicativo do esforço do país para apoiar os bens e serviços básicos à população. No gráfico da figura 4, são apresentadas as rúbricas da despesa pública em \% do PIB em 2010 e 2019. Neste âmbito, os dados indicam uma tendência à redução das despesas em \% do PIB. Contudo, em Portugal 0 peso das despesas nestas categorias essenciais é inferior à média europeia verificando-se, comparativamente, uma queda mais acentuada. Adicionalmente, ao nível da proteção ambiental, esta parcela da despesa, no período em causa, indica uma tendência de redução em Portugal, contrária à tendência de subida verificada na média da UE27.

Figura 4. Despesas públicas em \% do PIB

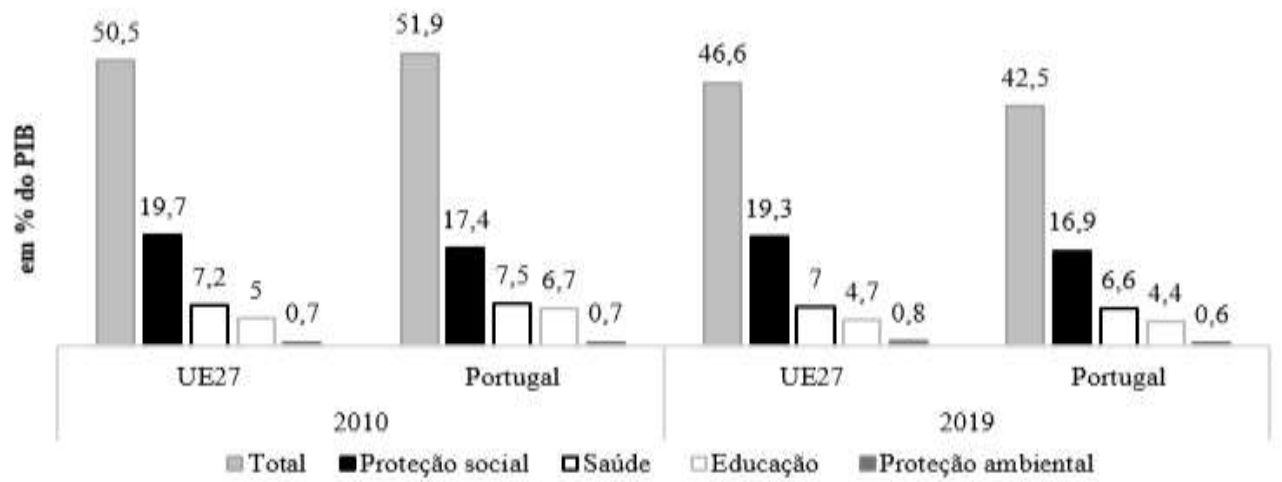

Fonte: elaboração própria com base em Eurostat database 


\subsection{ODS 6 - Água potável e saneamento}

0 ODS 6 visa garantir a disponibilidade e a gestão sustentável da água potável e do saneamento para todos. Isto indica que o objetivo será garantir a acessibilidade ao consumo seguro de água, bem como ao saneamento e higiene equitativos. Neste âmbito, a Agenda 2030 objetiva, também, melhorar a qualidade da água o que significa reduzir as águas residuais não tratadas, reduzir a poluição e despejo de produtos químicos e materiais perigosos. Neste âmbito, apresentamos a evolução que ocorreu na proporção da população residente que vive sem condições sanitárias no interior do alojamento (em \% do total) (e que também se insere no ODS 1). A figura 5 indica que, neste indicador, Portugal está melhor posicionado que média da UE27 tendo alcançado, em 2019, uma proporção de $0.5 \%$ da população a viver sem condições sanitárias, enquanto a média da UE27 situava-se em 1.6\%.

Figura 5. Proporção da população que vive sem condições sanitárias ${ }^{1}$

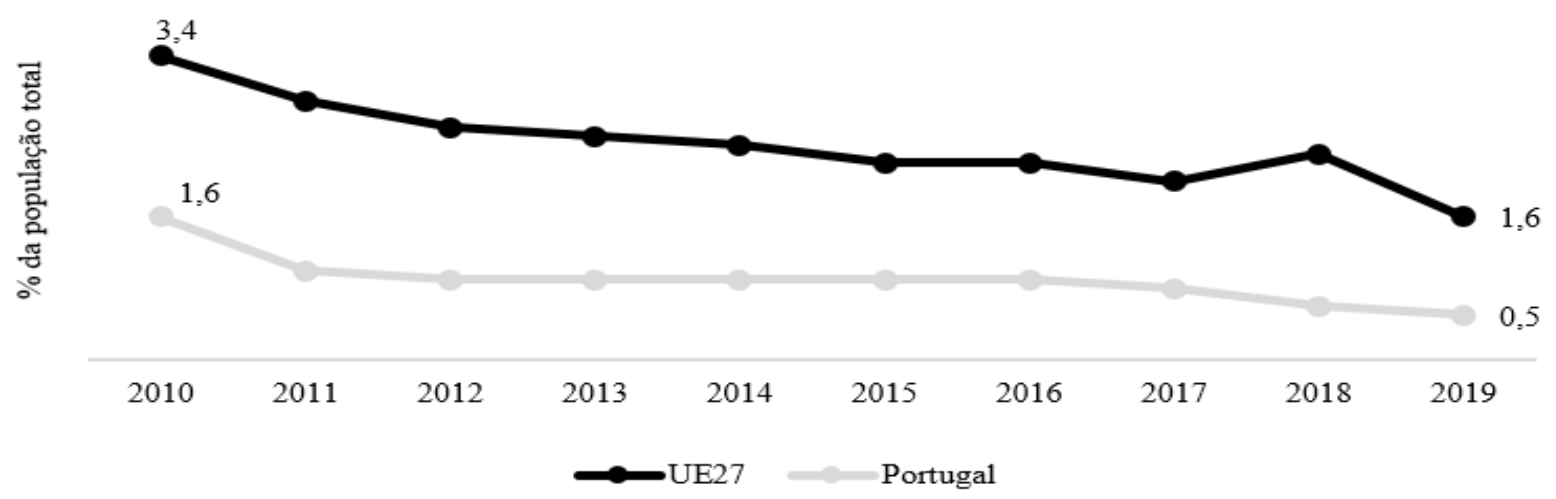

${ }^{1}$ Com falta de pelo menos uma das condições: banheira, duche, retrete no interior da habitação.

Fonte: elaboração própria com base em Eurostat database

\subsection{ODS 7 - Energias renováveis e acessíveis}

0 consumo de energia, com base em fontes de recursos naturais fósseis, constitui uma das principais fontes de poluição e aquecimento global, exercendo uma forte pressão sobre 0 planeta e a sua sustentabilidade. Nesse sentido, é necessário definir estratégias e implementar sistemas mais eficientes, limpos e renováveis. 0 ODS 7 visa garantir 0 acesso universal a fontes de energia fiáveis, sustentáveis e modernas estabelecendo metas para aumentar a eficiência e 0 peso das energias renováveis no consumo total de energia, bem como para reforçar a cooperação internacional para promover e facilitar a Investigação e Desenvolvimento (I\&D) tecnológico nesta área.

Considerando que 0 uso de energias renováveis constitui um dos princípios fundamentais da EC e que, segundo Schroeder et al. (2018) contribui de forma direta para 0 cumprimento das metas e ODS, apresentamos "o peso (em \%) da energia renovável no consumo final bruto de energia" (figura 6). Neste contexto, Portugal, em comparação com a média da UE27, apresenta resultados significativamente superiores, em todo 0 período, quer em termos totais, quer em termos segmentados (transporte, eletricidade $\mathrm{e}$ 
aquecimento e refrigeração). Entre 2010 e 2019, o peso da energia proveniente de fontes renováveis, no consumo final bruto de energia, aumentou de $24,2 \%$ para $30,6 \%$. Em termos segmentados, o maior acréscimo verificou-se na categoria eletricidade com um aumento de quase 13,2 p.p., 3,6 nos transportes e 7,8 p.p. no aquecimento e refrigeração.

Figura 6. Percentagem de energia renovável no consumo final bruto de energia (por categorias)

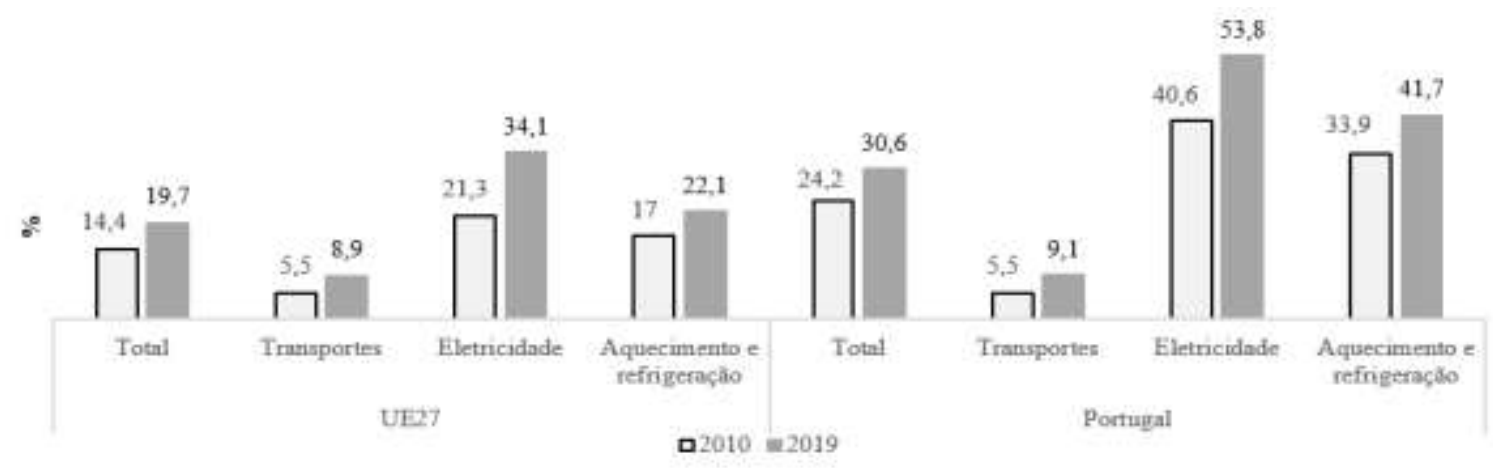

Fonte: elaboração própria com base em Eurostat database

\subsection{ODS 8 - Trabalho digno e crescimento económico}

0 ODS 8 tem como metas promover 0 crescimento económico inclusivo e sustentável, o emprego pleno e o trabalho digno para todos. Portanto, a par de medidas que promovam o crescimento económico, a produtividade, o emprego, a inovação e desenvolvimento tecnológico, é necessário garantir uma maior eficiência e sustentabilidade da produção, consumo e utilização de recursos. Neste âmbito, apresenta-se a evolução da taxa de crescimento do PIB per capita (quadro 3) e o consumo interno de materiais (figura 7). Este indicador também é considerado no ODS 12.
Na última década, comparando a evolução da taxa de crescimento do PIB per capita em Portugal com a média da UE, observa-se, nas fases recessivas do ciclo económico, uma queda mais acentuada do PIB per capita em Portugal. Em contrapartida, nas fases expansivas a taxa de crescimento em Portugal tende a ser superior à média europeia (quadro3).

Segundo o Instituto Nacional de Estatística ([INE], 2020) é importante ter conhecimento da evolução do PIB quando se analisa o consumo interno de materiais.

Quadro 3. Evolução da taxa de crescimento real do PIB per capita

\begin{tabular}{lccccccccccc}
\hline & 2010 & 2011 & 2012 & 2013 & 2014 & 2015 & 2016 & 2017 & 2018 & 2019 & 2020 \\
\hline UE27 & 2 & 1,7 & $-0,9$ & $-0,2$ & 1,4 & 2,1 & 1,8 & 2,6 & 2 & 1,3 & $-6,3$ \\
Portugal & 1,7 & $-1,6$ & $-3,7$ & $-0,4$ & 1,3 & 2,2 & 2,3 & 3,8 & 2,8 & 2,1 & $-7,8^{\mathrm{e}}$ \\
\hline
\end{tabular}

e - estimativa

Fonte: elaboração própria com base em Eurostat database 
0 consumo interno de materiais mede a quantidade total de materiais utilizada diretamente pela economia. A comparação desse indicador com o PIB dá indicação se o crescimento económico resulta de uma utilização mais eficiente dos materiais extraídos do meio ambiente (desmaterialização) ou de uma utilização mais intensa de materiais (INE, 2020).

Entre 2010 e 2013, período da crise financeira, o consumo interno de materiais em Portugal caiu cerca de $24 \%$ o que estará associada à contração da economia (quadro 3) e, sobretudo, à forte queda do setor da construção (ramo de atividade em que se regista uma utilização mais intensiva de materiais) (INE, 2020). Contudo, a partir de 2013, com a retoma do crescimento económico, o consumo interno de materiais volta a subir, acima do crescimento do PIB e mais acentuadamente que a média europeia (figura 7). No que respeita à evolução de 201019 , os dados indicam uma queda de 2,4 p.p. neste indicador. Contudo, em todo o período, 0 consumo interno de materiais em Portugal mantem-se significativamente acima da média da UE27, divergindo dessa média desde 2013 (figura 7). Adicionalmente, de acordo com 0 INE (2020), desde 2016 que este indicador não apresenta "desmaterialização" do crescimento económico pois a taxa de consumo interno de matérias tem verificado um crescimento superior ao do PIB.

Figura 7. Consumo interno de materiais

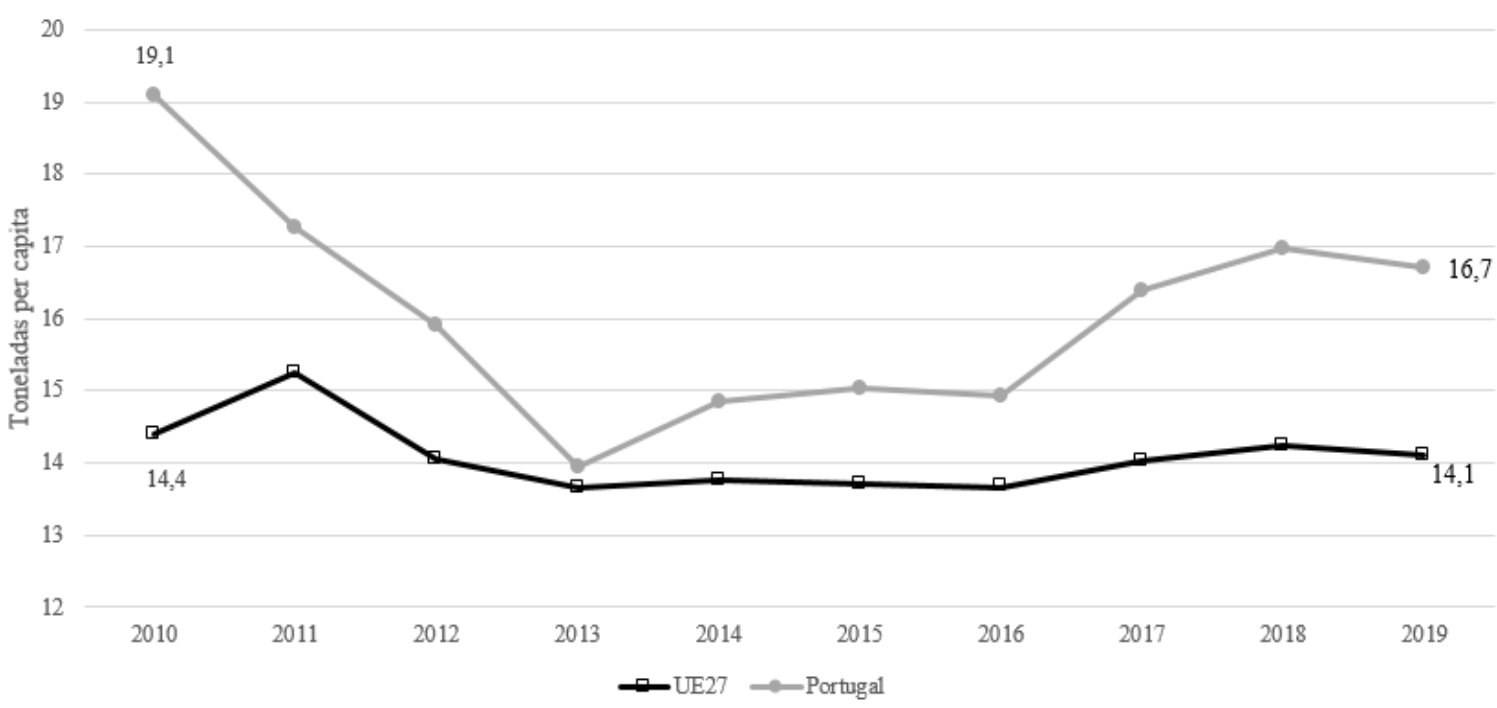

Fonte: elaboração própria com base em Eurostat database

No âmbito do ODS 8 insere-se também a promoção do emprego e trabalho digno. Neste contexto, apresenta-se a taxa de emprego total da população, entre os 20 e os 64 anos, para 0 qual a UE estabeleceu como meta atingir os $75 \%$ em 2020. 
Quadro 4. Taxa de emprego total

\begin{tabular}{lccccccccccc}
\hline & 2010 & 2011 & 2012 & 2013 & 2014 & 2015 & 2016 & 2017 & 2018 & 2019 & 2020 \\
\hline UE27 & 67,8 & 67,9 & 67,6 & 67,5 & 68,2 & 69,1 & 70,1 & 70,3 & 72,4 & 73,1 & 72,4 \\
Portugal & 70,3 & 68,8 & 66,3 & 65,4 & 67,6 & 69,1 & 70,6 & 73,4 & 75,4 & 76,1 & 74,7 \\
\hline
\end{tabular}

Fonte: elaboração própria com base em Eurostat database

Neste contexto, a taxa de emprego registou valores inferiores à média europeia no período da crise económica e do resgate financeiro, tendo evoluído positivamente desde 2014 e para níveis superiores à média da UE27. Em 2020, a taxa de emprego registou uma queda, relativamente ao ano anterior, quer em Portugal quer ao nível da UE27, o que deverá estar associado à crise pandémica.

\subsection{ODS 9 - Indústria, inovação e infraestruturas}

Para se alcançar DS é fundamental investir em inovação e I\&D de forma a que os processos industriais e produtivos transitem para processos mais limpos e sustentáveis. É também necessário colocar a inovação ao serviço da construção e disponibilização de infraestruturas resilientes que promovam 0 desenvolvimento económico e a acessibilidade, de todos os cidaçãos, a serviços fundamentais. Estes constituem os objetivos do ODS 9 indústria, inovação e infraestruturas. Este ODS integra 12 indicadores dos quais apresentamos a emissão de Dióxido de Carbono $\left(\mathrm{CO}_{2}\right)$ por unidade de Valor Acrescentado Bruto (VAB) (figura 8), a despesa em I\&D em \% do PIB (figura 9) e o número de investigadores Equivalente a Tempo Integral (ETI) em \% da população ativa (figura 10).

A intensidade carbónica da economia é medida pela comparação entre as emissões de $\mathrm{CO}_{2}$ e a variação do VAB (INE, 2020). Considerando a figura 8, as emissões de $\mathrm{CO}_{2}$ em Portugal são superiores à média da UE27 desde 2014. Apesar disso, e acompanhando a tendência na UE27, entre 2008 e 2019, verificou-se uma queda de cerca de $25 \%$ na emissão de $\mathrm{CO}_{2}$ por unidade de VAB.

Figura 8. Emissão de CO2 por unidade de valor acrescentado (Kg de CO2 /€)

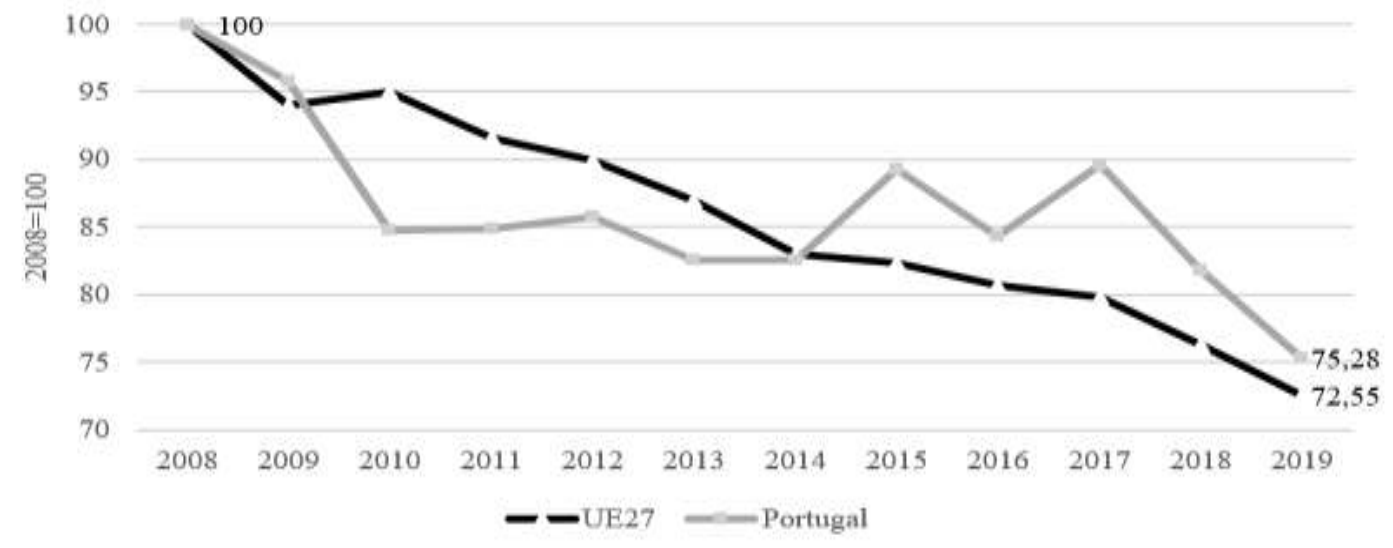

Nota: o valor de 2019 para a UE27 é estimado

Fonte: elaboração própria com base em Eurostat database 
No que respeita à $I \& D$, para os indicadores apresentados nas figuras 9 e 10, Portugal apresenta um desempenho abaixo da média da UE27. Em termos de peso da despesa em I\&D no PIB, esse indicador evoluiu em sentido descendente (de 1.54\% em 2010 para 1.40\% em 2019), contrariamente à media europeia que cresceu de 1,97 para 2.2\% (figura 9). Em termos de recursos humanos, entre 2010 e 2019, o número de investigadores, ETI em \% da população ativa, evoluiu positivamente, embora continue abaixo da média europeia (figura 10).

Figura 9. Despesas em I\&D em \% do PIB Figura 10. Pessoal em I\&D - ETI em \% da população ativa

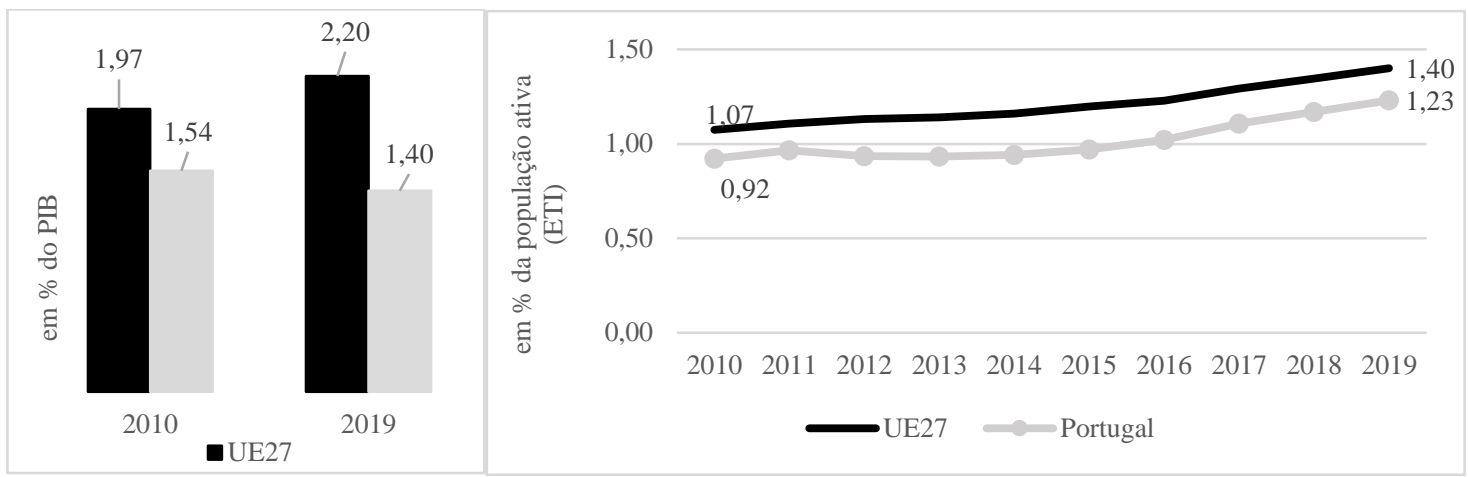

Nota: os valores de 2019 são provisórios

Fonte: elaboração própria com base em Eurostat database

\subsection{ODS 10 - Reduzir as desigualdades no interior dos países e entre os países}

As sociedades atuais caraterizam-se por elevados níveis de desigualdade, quer ao nível dos diferentes países, quer dentro dos países uma vez que existem discriminações e diferentes níveis de oportunidade com base no género, idade, deficiência, raça ou religião. Com este objetivo, seus indicadores e metas, pretende-se a redução dessas desigualdades.
O ODS 10, reduzir as desigualdades no interior dos países e entre países, insere-se, segundo Schroder et al. (2018), na categoria em que progressos registados no ODS poderão potenciar a aceitação e implementação das práticas de EC. Assim, no contexto do ODS 10 apresentamos 0 indicador "desigualdades na distribuição do rendimento (S80/S20)" (quadro 5).

Quadro 5. Desigualdade na distribuição do rendimento (S80/S20)

\begin{tabular}{lcccccccccc}
\hline & $\mathbf{2 0 1 0}$ & $\mathbf{2 0 1 1}$ & $\mathbf{2 0 1 2}$ & $\mathbf{2 0 1 3}$ & $\mathbf{2 0 1 4}$ & $\mathbf{2 0 1 5}$ & $\mathbf{2 0 1 6}$ & $\mathbf{2 0 1 7}$ & $\mathbf{2 0 1 8}$ & $\mathbf{2 0 1 9}$ \\
\hline UE27 & 4,89 & 4,99 & 4,98 & 5,05 & 5,22 & 5,22 & $5,16^{\mathrm{e}}$ & 5,03 & $5,05^{\mathrm{e}}$ & $4,99^{\mathrm{e}}$ \\
Portugal & 5,56 & 5,68 & 5,82 & 6,01 & 6,23 & 6,01 & 5,88 & 5,75 & 5,22 & 5,16 \\
\hline \multicolumn{8}{c}{} \\
& \multicolumn{1}{c}{ e- valor estimado } & & & & &
\end{tabular}

Fonte: elaboração própria com base em Eurostat database 
A análise da evolução do rácio indica que as desigualdades se acentuaram no período da crise e do resgaste financeiro ${ }^{29}$. A partir de 2015 observa-se uma tendência descendente no índice. Quando se compara Portugal com a média da UE27, é possivel indicar uma redução do diferencial a favor do nosso país. Não obstante, os níveis de desigualdade ainda são superiores em Portugal indicando que, em média, os $20 \%$ mais ricos recebem rendimentos 5.16 vezes superiores aos $20 \%$ mais pobres.

\subsection{ODS 11 - Cidades e comunidades sustentáveis}

O ODS 11 objetiva tornar as cidades e as comunidades mais inclusivas, seguras, resilientes e sustentáveis. Nesse sentido, entre outras metas, procura-se assegurar 0 acesso à habitação, melhorar a urbanização, desenvolver sistemas de transporte seguros, acessíveis, sustentáveis, bem como reduzir o impacto ambiental negativo per capita nas cidades. Neste âmbito, o indicador que apresentamos é o se refere à gestão de resíduos municipais - a taxa de reciclagem dos resíduos urbanos recolhidos (figura 11). No período de 2010-19, a evolução neste indicador, em Portugal, foi bastante positiva. Contudo, a taxa de reciclagem dos resíduos urbanos em Portugal situa-se muito abaixo da média da UE27.

Figura 11. Taxa de reciclagem dos resíduos urbanos recolhidos (em \% dos resíduos gerados)

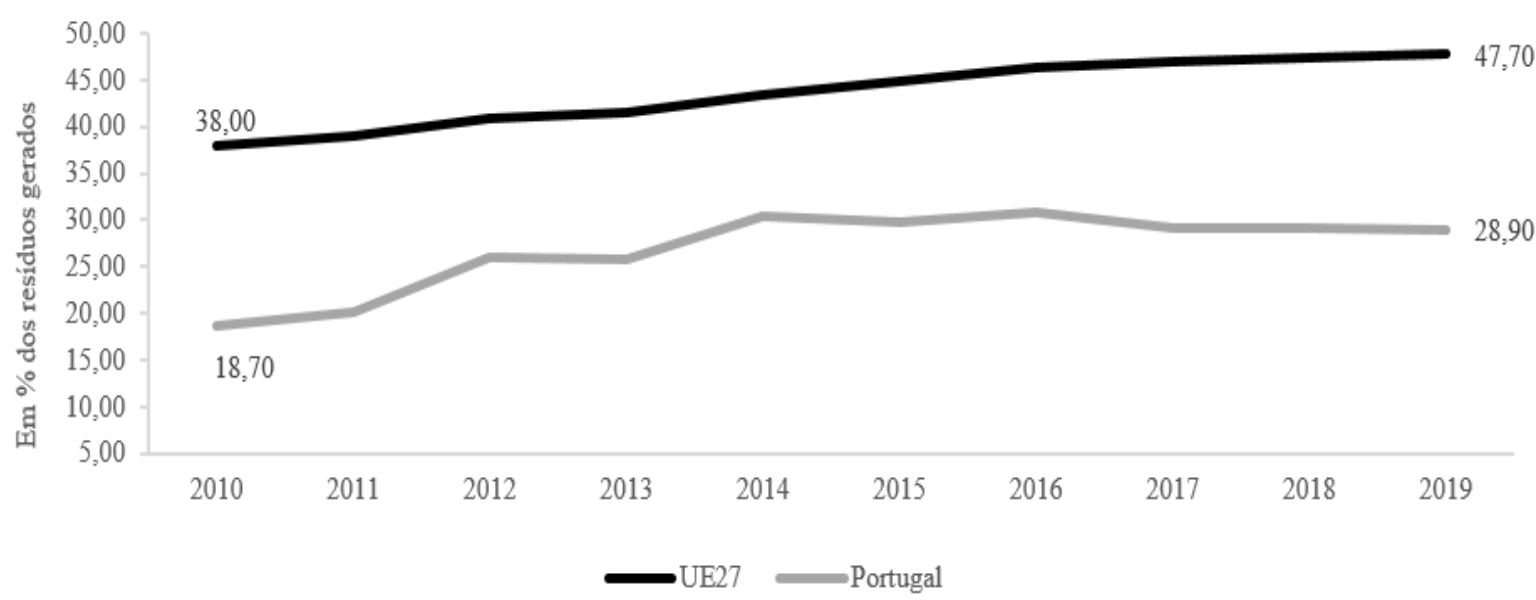

Nota: o valor de 2019 para a UE27 é estimado

Fonte: elaboração própria com base em Eurostat database

\subsection{ODS 12 - Produção e consumo sustentáveis}

Garantir padrões de consumo e de produção sustentáveis, nomeadamente através da gestão sustentável e o uso eficiente dos recursos naturais em toda a cadeia de valor, através de uma gestão ambientalmente equilibrada dos produtos químicos, dos resíduos e sua redução por meio da prevenção, reciclagem e reutilização, constituem algumas das metas definidas para o ODS 12. De uma forma clara, este ODS integra os princípios da EC visando promover as ações potenciadoras da adoção de sistemas produtivos e de consumo

${ }^{29} \mathrm{Em}$ 2011, Portugal foi intervencionado e apoiado pelo Fundo Monetário Internacional devido à situação de rutura das finanças públicas. 
sustentáveis, seja pela inovação tecnológica, seja pela melhoria da eficiência na utilização dos recursos e redução de resíduos. Neste contexto, a reciclagem e reutilização de materiais constituem um elemento fundamental para a proteção do ambiente e preservação dos recursos pelo que, segundo Schroeder e al. (2018), este ODS e as suas metas estão diretamente relacionadas e dependentes da implementação de sistemas da EC.
Considerando a taxa de utilização de material circular, que dá indicação da proporção de materiais reciclados incorporados nos novos produtos (figura 12), Portugal, com uma taxa de $2.2 \%$ (2019) de incorporação de material reciclado nos novos produtos, encontra-se muito abaixo da média europeia (com uma taxa de 11.9\%). Apresenta, contudo, uma ligeira tendência de subida no indicador.

Figura 12. Taxa de utilização de material circular (\%)

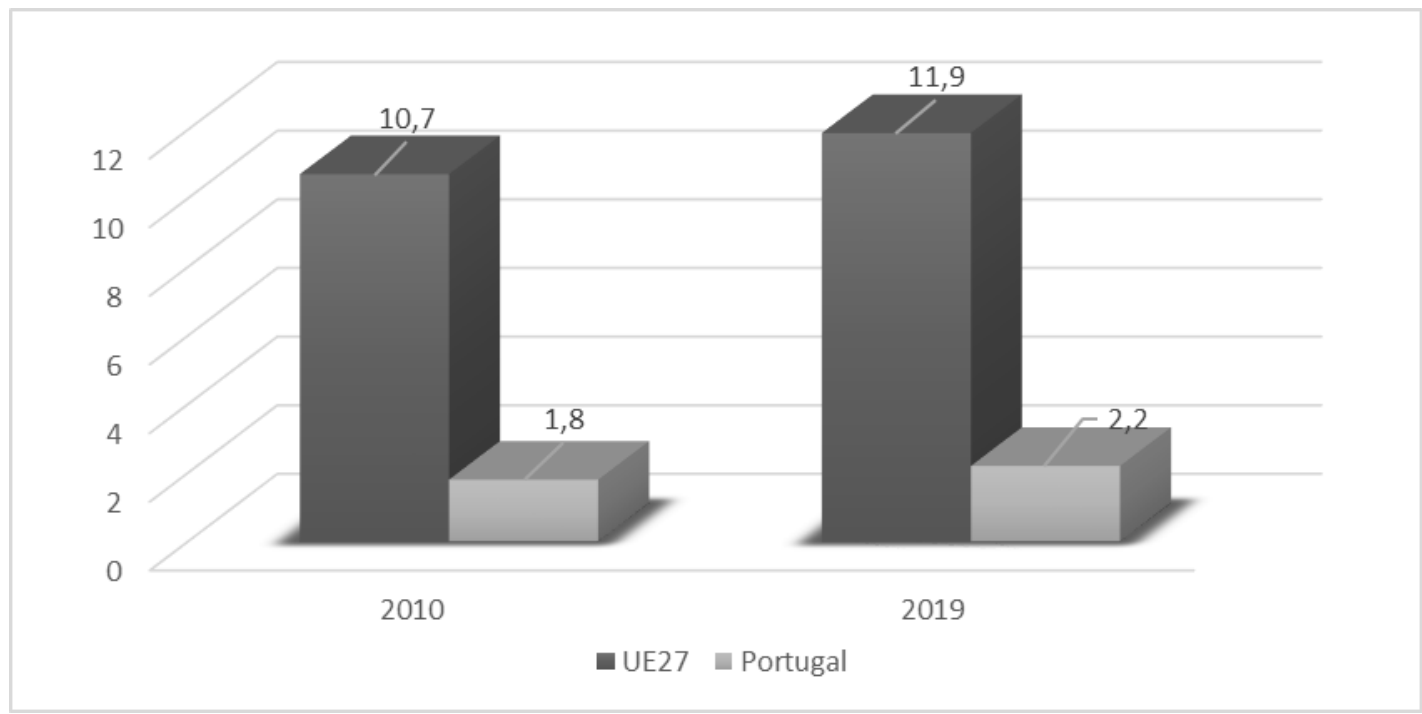

Nota: o valor de 2019 é estimado

Fonte: elaboração própria com base em Eurostat database

Em complemento à taxa de utilização de material circular, apresentamos, no quadro 6 , a taxa de reciclagem de embalagens. De acordo com o Eurostat database, a taxa de reciclagem de embalagens corresponde à parcela de resíduos de embalagens recicladas no total de todos os resíduos de embalagens gerados. Neste indicador Portugal também apresenta um desempenho inferior à média da UE27. Entre 2010-16 houve uma evolução positiva, mas desde então os valores regrediram para níveis de 2015.

Quadro 6. Taxa de reciclagem de embalagens

\begin{tabular}{lccccccccc}
\hline & $\mathbf{2 0 1 0}$ & $\mathbf{2 0 1 1}$ & $\mathbf{2 0 1 2}$ & $\mathbf{2 0 1 3}$ & $\mathbf{2 0 1 4}$ & $\mathbf{2 0 1 5}$ & $\mathbf{2 0 1 6}$ & $\mathbf{2 0 1 7}$ & $\mathbf{2 0 1 8}$ \\
\hline UE27 & 64 & 64,2 & 65,2 & 65,4 & 66,5 & 66,6 & 67,5 & 67,5 & $66,3^{\mathrm{e}}$ \\
Portugal & 55,5 & 58,4 & 56,9 & 61,5 & 61 & 57,1 & 60,9 & 55,3 & 57,6 \\
\hline
\end{tabular}

e - estimativa do Eurostat 


\subsection{ODS 13 - Ação climática}

Este objetivo determina a adoção de medidas destinadas a combater as alterações climáticas e os seus impactos, com particular enfâse e apoio aos países menos desenvolvidos.
Neste contexto, apresentamos, na figura 13, o indicador relativo à emissão de gases com efeitos de estufa. No período de 2010-18 não houve evolução positiva em Portugal não se registando uma redução dessas emissões, contrariamente à tendência de diminuição, embora pouco significativa, verificada na média da UE27.

Figura 13. Emissões de gases com efeitos de estufa (toneladas per capita)

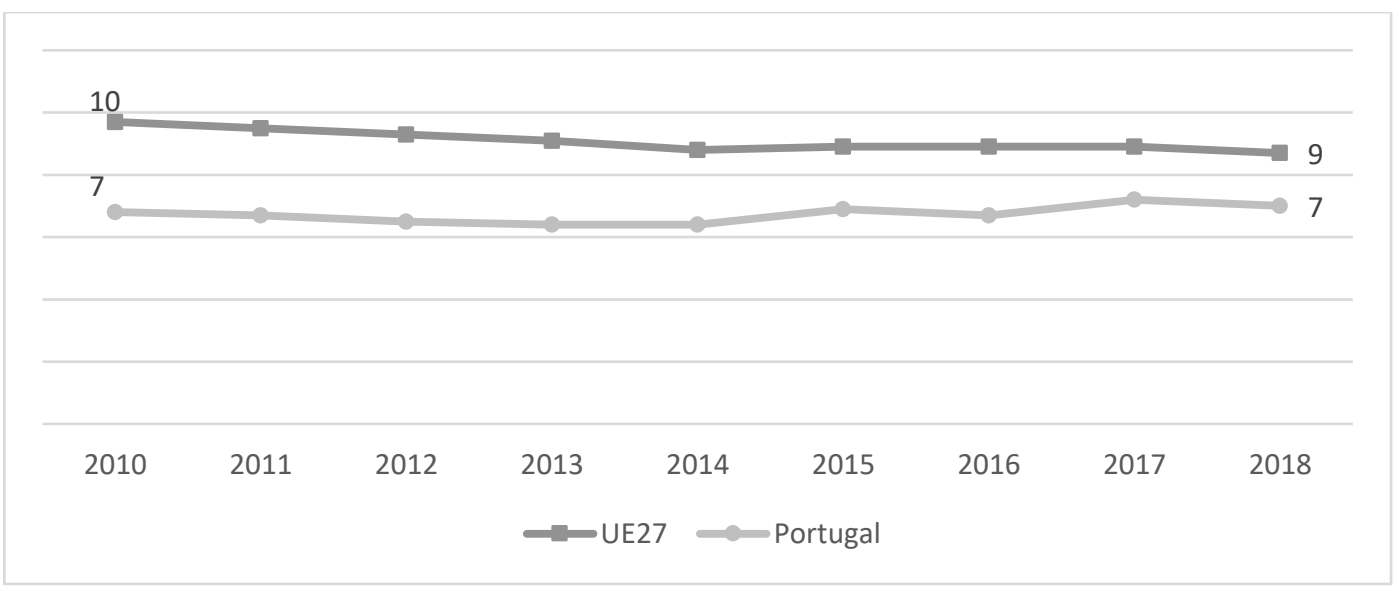

Fonte: elaboração própria com base em Eurostat database

\subsection{ODS 14 - Proteger a vida marinha e} ODS 15 - Proteger a vida terrestre

Os ecossistemas marinhos, bem como os terrestes, são fundamentais para a sobrevivência humana. Nesse sentido, o ODS 14 visa proteger e utilizar, de forma sustentável, os oceanos, rios e recursos marinhos. Por sua vez o ODS 15 procura proteger, restaurar e promover a conservação e o uso sustentável das florestas, do solo e da biodiversidade. Estes princípios também deverão ser integrados na definição e implementação de estratégias de redução da pobreza. Neste âmbito, apresentamos, no quadro 7 , a evolução ocorrida na superfície marinha protegida (em $\mathrm{Km}^{2}$ ) e no quadro 8 a superfície terrestre protegida $\left(\mathrm{em} \mathrm{Km}^{2}\right)$. Quer em termos de superfície marinha, quer em termos de superfície terrestre, Portugal apresenta uma evolução positiva e um rácio significativamente superior à média da UE27. 
Quadro 7. Superfície marinhas (em $\mathrm{Km}^{2}$ ) protegidas (designados no âmbito de Natura 2000) ${ }^{30}$

\begin{tabular}{l|r|r|r|r|r|r|r}
\hline & \multicolumn{1}{|c|}{$\mathbf{2 0 1 3}$} & \multicolumn{1}{c|}{$\mathbf{2 0 1 4}$} & \multicolumn{1}{c|}{$\mathbf{2 0 1 5}$} & \multicolumn{1}{c|}{$\mathbf{2 0 1 6}$} & \multicolumn{1}{c|}{$\mathbf{2 0 1 7}$} & \multicolumn{1}{c}{$\mathbf{2 0 1 8}$} & \multicolumn{1}{c}{$\mathbf{2 0 1 9}$} \\
\hline UE27 & 177483 & 244054 & 286145 & 308364 & 402552 & 419769 & 441001 \\
Portugal & 2619 & 2634 & 31885 & 31885 & 38052 & 38052 & 42434 \\
\hline
\end{tabular}

Fonte: elaboração própria com base em Eurostat database

Quadro 8. Superfície terrestre e marinha protegida (em \%)

\begin{tabular}{|l|c|c|}
\cline { 2 - 3 } \multicolumn{1}{c|}{} & 2013 & 2019 \\
\hline UE27 - área terrestre protegida & $18 \%$ & $18 \%$ \\
\hline Portugal - área terrestre protegida & $21 \%$ & $21 \%$ \\
\hline UE27 - área marinha protegida & $4 \%$ & $11 \%$ \\
\hline Portugal - área marinha protegida & $14 \%$ & $46 \%$ \\
\hline
\end{tabular}

Fonte: elaboração própria com base em Eurostat database

\subsection{ODS 16 - Paz, justiça e instituições} eficazes

O ODS 16 pretende o desenvolvimento de sociedades pacíficas e inclusivas para o DS, que possam ser o garante da equidade $\mathrm{e}$ acesso à justiça para todos, a inclusão e o respeito pelos direitos humanos. De acordo com a UN (2015), uma sociedade só poderá progredir, evoluir e promover o DS se as suas instituições forem eficazes, transparentes e responsáveis e promovam um Estado de direito e boa governação a todos os níveis. Neste contexto, apresenta-se 0 indicador "perceção de independência do sistema judicial" (quadro 9). Este indica que em Portugal, em 2019, 46\% dos inquiridos consideravam que a independência do sistema judicial é má ou muito má, situando-se 11 p.p. acima da média da UE27.

Quadro 9. Perceção de independência do sistema judicial (má ou muito má) (em \%)

\begin{tabular}{lcccc}
\hline & $\mathbf{2 0 1 6}$ & $\mathbf{2 0 1 7}$ & $\mathbf{2 0 1 8}$ & $\mathbf{2 0 1 9}$ \\
\hline UE27 & 38 & 36 & 34 & 35 \\
Portugal & 44 & 44 & 43 & 46
\end{tabular}

Fonte: elaboração própria com base em Eurostat database

\begin{abstract}
4.12. ODS 17 - Parcerias para a 0 DS é um desafio global que implica a implementação dos objetivos integração, parceria e o envolvimento dos países, governos, setor privado, indivíduos e sociedade civil. Nesse sentido, o ODS 17 incide
\end{abstract}

300 indicador mede a superfície dos sítios marinhos designados no âmbito de Natura 2000 e tem como objetivo de manter ou restaurar um estado de conservação favorável para tipos de habitat e espécies de interesse da UE. 
sobre as parcerias para a implementação dos objetivos. Neste âmbito, apresentamos na figura 14, o indicador "Ajuda Pública ao
Desenvolvimento (APD) ${ }^{31}$ em percentagem do Rendimento Nacional Bruto (RNB)".

Figura 14. Ajuda pública ao desenvolvimento (em \% do RNB)

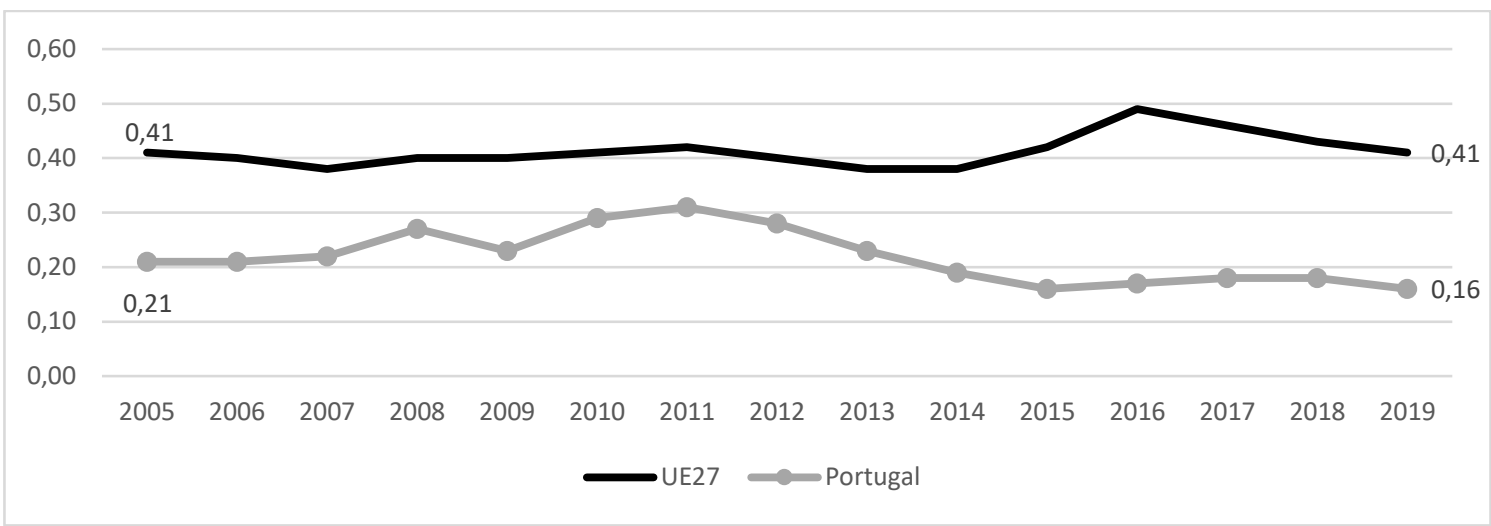

Nota: o valor de 2019 é um valor provisional

Fonte: elaboração própria com base em Eurostat database

No período de 2010 a 2019, a APD concedida por Portugal está muito abaixo da média da UE27 e muito longe do compromisso de atingir a meta de $0,7 \%$ do RNB. A partir de 2011 até 2015 verificou-se uma redução da APD, que poderá estar associado ao programa de ajustamento da economia portuguesa. A partir de 2015 melhorou, muito ligeiramente, até 2018. Contudo, em 2019 o valor (provisional) voltou a descer para $0,16 \%$ aumentando o diferencial em relação à média da UE27.

Outro indicador considerado no âmbito deste ODS é o "peso dos impostos ambientais no total das receitas fiscais" (figura 15). Este este rácio dá indicação da evolução da tributação sobre as atividades poluentes, isto é, os impostos cobrados sobre atividades com impactos negativos comprovados ${ }^{32}$ sobre 0 ambiente. No que se refere a este rácio, e para o período em análise, podemos observar uma tendência descendente no peso dos impostos ambientas nas receitas fiscais, quer em Portugal, quer na UE. Em 2010, em Portugal, estes impostos correspondiam a $8 \%$ do total das receitas fiscais, mas em 2019 tinham um peso de $7,33 \%$ (figura 15). Apesar dessa evolução verifica-se que em Portugal estes impostos têm maior peso relativo nas receitas fiscais, em comparação com a média europeia, o poderá ser indicativo de maiores níveis de atividade com impacto negativo no ambiente.
${ }^{31}$ De acordo com o Eurostat (2020), a APD consiste no apoio
concedido por organismos públicos (em forma de subvenções,
assistência técnica ou empréstimos concessionais, mais
favoráveis), destinada a promover o desenvolvimento económico
e bem-estar dos países em desenvolvimento.
32 De acordo com o Eurostat (2020), os impostos ambientais são
definidos como impostos cuja base tributária é uma unidade física (ou proxy da mesma) de algo que tem um impacto negativo comprovado e específico sobre o ambiente. As receitas fiscais ambientais provêm de quatro tipos de impostos: impostos sobre a energia (que contribuem com cerca de três quartos do total), impostos sobre os transportes (cerca de um quinto do total) $\mathrm{e}$ impostos sobre a poluição e os recursos naturais (cerca de $4 \%$ do total). 
Figura 15. Percentagem dos impostos ambientais no total das receitas fiscais

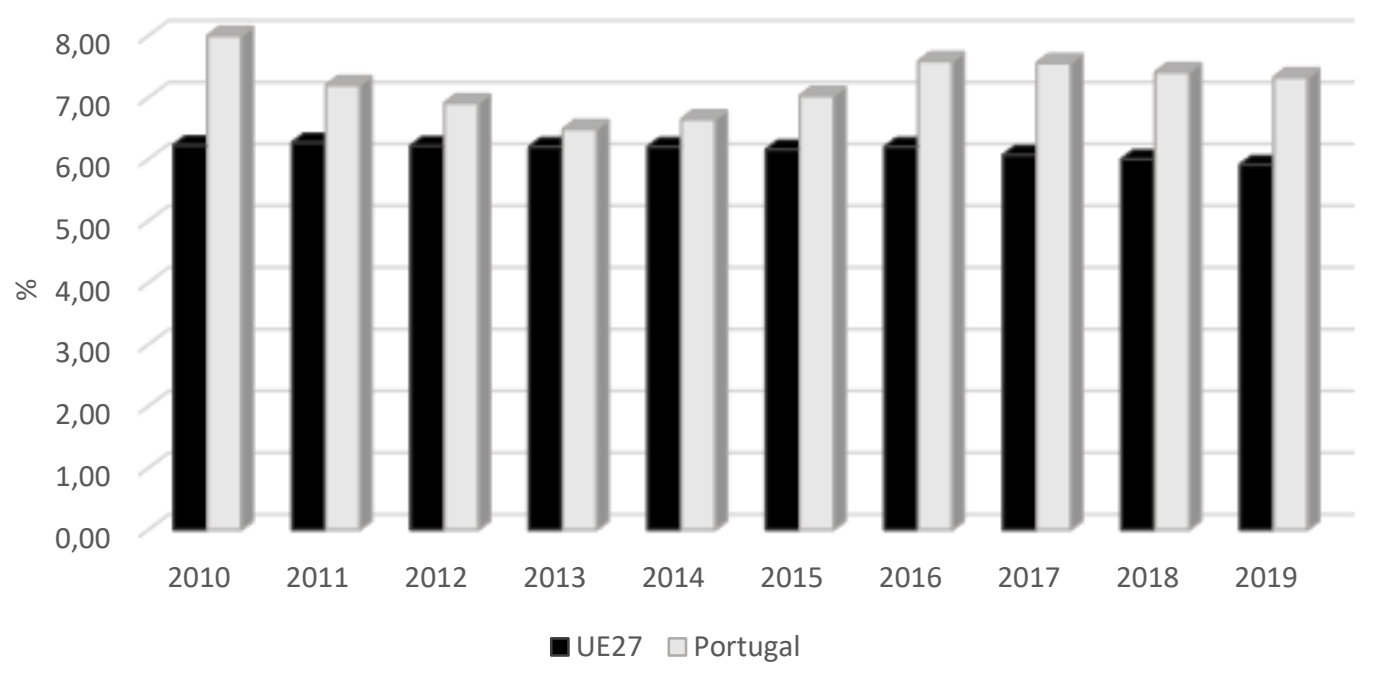

Fonte: elaboração própria com base em Eurostat database

A análise realizada indica que a posição relativa de Portugal é desfavorável comparativamente à média da UE27. Para a maioria dos indicadores, a evolução no período foi positiva, mas há ainda muito caminho a percorrer. 0 quadro 10 apresenta um resumo da posição relativa de Portugal, face à média da UE27, e o sentido de evolução ocorrido no período em análise.

Quadro 10. Posicionamento relativo nos indicadores analisados

\begin{tabular}{|l|l|l|}
\hline ODS & Indicador & $\begin{array}{l}\text { Posição relativa face à média da } \\
\text { UE27 e evolução entre 2010-19 }\end{array}$ \\
\hline \multirow{2}{*}{ ODS 1 } & $\begin{array}{l}\text { População em risco de pobreza, após transferências } \\
\text { sociais }\end{array}$ & $\begin{array}{l}\text { Posição relativa desfavorável. } \\
\text { Evolução positiva }\end{array}$ \\
\cline { 2 - 4 } & $\begin{array}{l}\text { Despesas públicas em serviços essenciais (\% do } \\
\text { PIB) }\end{array}$ & Posição relativa desfavorável. \\
ODS 6 & $\begin{array}{l}\text { Proporção da população que vive sem condições } \\
\text { sanitárias }\end{array}$ & Posição relativa favorável. \\
\hline ODS 1 & $\begin{array}{l}\text { Percentagem de energia renovável no consumo final } \\
\text { bruto de energia }\end{array}$ & Posição relativa favorável. \\
\hline ODS 7 & $\begin{array}{l}\text { Evolução da taxa de crescimento real do PIBpc } \\
\text { Taxa de emprego total }\end{array}$ & Indefinido. \\
\hline ODS 8 & $\begin{array}{l}\text { Posição relativa favorável. } \\
\text { Evolução positiva }\end{array}$ \\
\hline
\end{tabular}




\begin{tabular}{|c|c|c|}
\hline $\begin{array}{l}\text { ODS } 8 \text { e } \\
12\end{array}$ & Consumo interno de materiais & Evolução desfavorável desde 2013. \\
\hline $\begin{array}{l}\text { ODS } 9 \text { e } \\
\text { ODS } 7\end{array}$ & Emissão de CO2 por unidade de valor acrescentado & $\begin{array}{l}\text { Posição relativa desfavorável. } \\
\text { Evolução positiva. }\end{array}$ \\
\hline \multirow{2}{*}{ ODS 9} & Despesa em I\&D (em \% do PIB) & $\begin{array}{l}\text { Posição relativa desfavorável. } \\
\text { Evolução desfavorável. }\end{array}$ \\
\hline & $\begin{array}{l}\text { Investigadores equivalente a ETI (\% da população } \\
\text { ativa) }\end{array}$ & $\begin{array}{l}\text { Posição relativa desfavorável. } \\
\text { Evolução positiva. }\end{array}$ \\
\hline ODS 10 & $\begin{array}{l}\text { Desigualdade na distribuição do rendimento } \\
\text { (S80/S20) }\end{array}$ & $\begin{array}{l}\text { Posição relativa desfavorável. } \\
\text { Evolução positiva. }\end{array}$ \\
\hline ODS 11 & Taxa de reciclagem dos resíduos urbanos recolhidos & $\begin{array}{l}\text { Posição relativa desfavorável. } \\
\text { Evolução positiva. }\end{array}$ \\
\hline \multirow[b]{2}{*}{ ODS 12} & Taxa de utilização de material circular & $\begin{array}{l}\text { Posição relativa desfavorável. } \\
\text { Evolução positiva }\end{array}$ \\
\hline & Taxa de reciclagem de embalagens & $\begin{array}{l}\text { Posição relativa desfavorável. } \\
\text { Evolução positiva de } 2010-16 \text { mas } \\
\text { negativa em } 2017\end{array}$ \\
\hline ODS 13 & $\begin{array}{l}\text { Emissões de gases com efeitos de estufa (toneladas } \\
\text { per capita) }\end{array}$ & $\begin{array}{l}\text { Posição relativa desfavorável. } \\
\text { Manutenção do indicador }\end{array}$ \\
\hline ODS 14 & $\begin{array}{l}\text { Superfícies marinhas protegidas }\left(\mathrm{em} \mathrm{Km}^{2}\right) \\
\text { Área marinha protegida (em \%) }\end{array}$ & $\begin{array}{l}\text { Posição relativa favorável. } \\
\text { Evolução positiva }\end{array}$ \\
\hline ODS 15 & Área terreste protegida (em \%) & $\begin{array}{l}\text { Posição relativa favorável. Evolução } \\
\text { positiva. }\end{array}$ \\
\hline ODS 16 & $\begin{array}{l}\text { Perceção de independência do sistema judicial (má } \\
\text { ou muito má) }\end{array}$ & $\begin{array}{l}\text { Posição relativa desfavorável. } \\
\text { Evolução desfavorável. }\end{array}$ \\
\hline \multirow[t]{2}{*}{ ODS 17} & Ajuda pública ao desenvolvimento em $\%$ do RNB & $\begin{array}{l}\text { Posição relativa desfavorável. } \\
\text { Evolução desfavorável. }\end{array}$ \\
\hline & $\begin{array}{l}\text { Percentagem dos impostos ambientais no total das } \\
\text { receitas fiscais }\end{array}$ & Posição relativa desfavorável. \\
\hline
\end{tabular}

Fonte: elaboração própria 
A Agenda 2030 e os ODS constituem um desafio global, multidisciplinar e transformativo. Para se alcançar o DS nenhuma dimensão pode ser esquecida. Processos de produção e consumo sustentáveis, a par da eficiência energética e eficiente utilização de recursos, preservação do ambiente e dos ecossistemas, justiça e equidade social e geracional, são questões e dimensões fundamentais que implicam uma ação e comprometimento individual, coletivo e global para se alcançar DS e melhores condições de vida para todos.

Um dos objetivos deste trabalho foi analisar e discutir, pela revisão de literatura relevante, os conceitos e relações entre a EC e o DS e a sua relevância para 0 alcance dos objetivos da Agenda 2030. A EC, como estratégia inserida no conceito de DS, tem sido considerada como um modelo capaz de substituir o atual sistema linear (extrair-consumir-descartar). Apesar de ainda ser uma questão assente em alguma controvérsia, a literatura indica que vários investigadores e organizações consideram que a implementação das práticas e princípios da EC constitui uma abordagem fundamental para atingir vários objetivos da Agenda 2030 (Comissão Europeia, 2020; Ellen MacArthur Foundation, 2017; Ghisellini et al. 2016; Kirchherr et al. 2017; Korhonen et al. 2018; Murray, et al. 2017; Schroeder et al. 2018; Yuan et al. 2006).

Além de discutir a relação entre a EC e o DS, este trabalho tinha outro objetivo: fazer uma análise à evolução ocorrida em Portugal, num conjunto de indicadores de DS, e compará-la com a média europeia. Nesta análise foram considerados 20 indicadores. Dentro deste conjunto, Portugal apresenta uma posição relativa mais favorável, que a média da UE27, em apenas cinco, "na proporção de população que vive sem condições sanitárias", no "peso da energia renovável no consumo final bruto de energia", na "taxa de emprego total", "na área marinha protegida" e na "área terrestre protegida". Para todos os restantes indicadores analisados, Portugal apresenta uma posição relativa desfavorável em comparação com a média da UE27. Em alguns desses indicadores a evolução ocorreu no sentido contrário ao desejável. Apesar de se verificar uma evolução positiva em vários indicadores, e de termos uma sociedade cada vez mais consciente e atenta a produtos, processos e entidades "sustentáveis" e dos pressupostos da EC e do DS serem progressivamente reconhecidos e defendidos, podemos concluir que ainda há muito caminho a percorrer. Com efeito, este trabalho constitui um contributo para 0 conhecimento e diagnóstico à posição relativa de Portugal, no contexto europeu, no que respeita ao alcance dos ODS e suas metas, podendo servir de parâmetro para identificar e direcionar estratégias e medidas de política para ultrapassar o posicionamento e trajetória desfavorável identificada em vários indicadores.

Para finalizar, não podemos deixar de apontar uma das principais limitações do trabalho. Nesta análise, 0 número de indicadores selecionado é reduzido e, além disso, não foram considerados os ODS 2,3,4 e 5. Nesse sentido, em trabalhos futuros será importante aprofundar a análise integrando mais objetivos e indicadores, bem como alargar a análise comparativa a um maior número de países. 

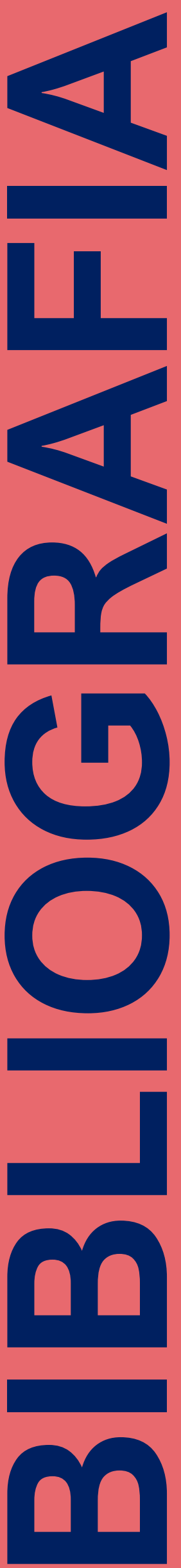

Aid, G.; Lazarevic, D.; Kihl, A. (2016). Waste to resources: Moving toward the 2030 sustainable development goals. In Proceedings of the Linnaeus Eco-Tech, Kalmar, Sweden, 21-23 November 2016; pp. 1-19.

Bonciu, F. (2014). The European economy: from a linear to a circular economy. Romanian Journal of European Affairs, Vol. 14, No. 4, pp. 78-91

Borrello, M., Pascucci, S. \& Cembalo, L. (2020). Three Propositions to Unify Circular Economy Research: A Review. Sustainability, 12 (10), 4069. https://doi.org/10.3390/su12104069

Busu, M.; Nedelcu, A. (2017). Sustainability and Economic Performance of the Companies in the Renewable Energy Sector in Romania. Sustainabilty, 10 (1), 8.https://doi.org/10.3390/su10010008

Cecchin, A., Salomone, R., Deutz, P., Raggui, A. \& Cutaia, L. (2021). What Is in a Name? The Rising Star of the Circular Economy as a ResourceRelated Concept for Sustainable Development. Circular Economy and Sustainability. https://doi.org/10.1007/s43615-021-00021-4

Curwell, S. \& Cooper, I. (1998) The implications of urban sustainability. Building Research \& Information, 26:1, pp. 17-28, https://doi.org/10.1080/096132198370074

D’Amato, D. (2021). Sustainability Narratives as Transformative Solution Pathways: Zooming in on the Circular Economy. Circular Economy and Sustainability. https://doi.org/10.1007/s43615-021-00008-1

De Man, R. \& Friege, H. (2016). Circular economy: European policy on shaky ground. Waste Management and Research, v. 34, n. 2, pp: 93-95.

Elkington, J. (1994). Triple bottom line revolution: reporting for the third millennium. Australian CPA, v. 69, p. 75.

Ellen MacArthur Foundation (2015). Growth within: a circular economy vision for a competitive Europe. Disponivel em https://www.ellenmacarthurfoundation.org/assets/downloads/publicatio ns/EllenMacArthurFoundation Growth-Within July15.pdf

Ellen MacArthur Foundation (2017). Circular Economy. Disponível em https://www.ellenmacarthurfoundation.org/circular-economy/concept.

European Commission (2020). Leading the way to a global circular economy: state of play and outlook. Commission Staff Working Document. SWD (2020) $\quad 100 \quad$ final. Disponivel em https://ec.europa.eu/environment/circulareconomy/pdf/leading way gl obal circular economy.pdf .

European Environment Agency (2016). Circular economy in Europe. Developing the knowledge base. EEA Report No 2/2016. Luxembourg: Publications Office of the European Union. 
Eurostat (2021). Your Key to European Comission. Disponível em https://ec.europa.eu/eurostat/data/database. Acedido em março de 2021.

Gentiloni, P. (2020). Foreword of Commissioner Gentiloni. In: Sustainable development in the European Union. Monitoring report on progress towards the SDGs in an EU context. Publications Office of the European Union, Luxembourg. Disponivel em https://ec.europa.eu/eurostat/web/products-statistical-books/-/KS-0220-202.

GIL, A. C. (2010). Como elaborar projetos de pesquisa. Atlas, $5^{\mathrm{a}}$ ed.

Ghisellini, P., Cialani, C., Ulgiati, S., 2016. A review on circular economy: the expected transition to a balanced interplay of environmental and economic systems. Journal of Cleaner Production, 114, pp.11-32.

Hysa, E.; Kruja, A.; Rehman, N.U. \& Laurenti, R. (2020). Circular economy innovation and environmental sustainability impact on economic growth: An integrated model for sustainable development. Sustainability 12 (12), 4831.https://doi.org/10.3390/su12124831

INE (2020). Objetivos de Desenvolvimento Sustentável - Agenda 2030. Indicadores para Portugal - 2010/2019

Lieder, M. \& Rashid, A. (2016). Towards circular economy implementation: A comprehensive review in context of manufacturing industry. J. Clean. Prod., 115, 36-51.https://doi.org/10.1016/j.jclepro.2015.12.042

Millar, N., McLaughlin, E., Börger, T. (2019). The Circular Economy: Swings and Roundabouts? Ecological Economics, 158, pp.11-19.

Mitchell, G. \& McDonald, A. (1995). PICABUE: A methodological framework for the development of indicators of sustainable development. The International Journal of Sustainable Development and World Ecology 2(2), pp.104-123.

Murray, A., Skene, K. \& Haynes, K. (2017). The Circular Economy: An Interdisciplinary Exploration of the Concept and Application in a Global Context. Journal of Business Ethics volume 140, pp. 369-380.

Nikolaou, I.E., Jones, N. \& Stefanakis, A. (2021). Circular Economy and Sustainability: the Past, the Present and the Directions Circular Economy and Sustainability. https://doi.org/10.1007/s43615-021-00030-3

Kirchherr, J., Reike, D., Hekkert, M., (2017). Conceptualizing the circular economy: an analysis of 114 definitions. Resources, Conservation \& Recycling, 127, pp. 221-232.

Khitous, F.; Strozzi, F.; Urbinati, A.; Alberti, F. (2020) A Systematic Literature Network Analysis of Existing Themes and Emerging Research Trends in Circular Economy. Sustainabilty,12 1633.https://doi.org/10.3390/su12041633 
Korhonen, J., Nuur, C., Feldmann, A., Birkie, S., (2018). Circular economy as an essentially contested concept. Journal of Cleaner Production, 175, pp. 544-552.

Prieto-Sandoval, V., Jaca, C., Ormazabal, M. (2018). Towards a consensus on the circular economy. Journal of Cleaner Production, v. 179, pp. $605-$ 615.

Richardson, R. J.(1999). Pesquisa social: métodos e técnicas. Atlas.

Schroeder, P., Anggraeni, K., Weber, U. (2018). The relevance of circular economy practices to the sustainable development goals. Journal of Industrial Ecology, Volume 23, n. ${ }^{0} 1$, pp.77-95

Suárez-Eiroa, B., Fernández, E., Méndez-Martínez, G. \& Soto-Oñate, D (2019). Operational principles of circular economy for sustainable development: Linking theory and practice. Journal of Cleaner Production, 214, pp. 952-961

United Nations (1987). Report of the World Commission on Environment and Development "Our Common Future" - document A/42/427. Disponível em

https://sustainabledevelopment.un.org/content/documents/5987ourcommon-future.pdf

United Nations (1992). United Nations Conference on Environment \& Development. Agenda $21 . \quad$ Disponivel em https://sustainabledevelopment.un.org/content/documents/Agenda21.p df.

United Nations (2002). World Summit on Sustainable Development Johannesburg Declaration on Sustainable Development. Disponível em http://www.un-documents.net/jburgdec.htm

United Nations (2012). Resolution adopted by the General Assembly - The future we want (A/RES/66/288). Disponivel em https://sustainabledevelopment.un.org/rio20/futurewewant

United Nations (2015). Resolution adopted by the General Assembly Transforming our world: the 2030 Agenda for Sustainable Development (A/RES/70/1). https://sustainabledevelopment.un.org/post2015/transformingourworld . Acedido a 5/08/2020.

Vasiljevic-Shikaleska, A., Gjozinska, B., \& Stojanovikj, M. (2017). The circular economy - a pathway to sustainable future. Journal of Sustainable Development, 7(17), pp. 13-30.

Yuan, Z., Bi, J. Moriguichi, Y. (2006). The Circular Economy: A New Development Strategy in China. Journal of Industrial Ecology, vol. 10, Issue 1-2, pp. 4-8. 